\title{
STRATEGIC COMMITMENT VERSUS FLEXIBILITY IN A DUOPOLY WITH ENTRY AND EXIT
}

\author{
Francisco Ruiz-Aliseda* \\ Northwestern University
}

October 2003

\begin{abstract}
This paper examines how differences in the opportunity costs of assets employed by firms affect the tradeoff between the commitment to a particular course of action and the flexibility to revise past actions. The setup is characterized by two firms that have to decide at each instant of time whether to be in or out of an industry that is assumed to expand up to a maturity date uncertain to the companies, declining until it disappears thereafter. Firms differ only on the opportunity costs of the resources they possess, and thus their investments are not equally recoverable, which allows for the analysis of whether or not a firm benefits from competing with the assets whose outside option is most valuable. I characterize the path associated to the unique subgame perfect equilibrium of the game and pay special attention to the role of opportunity costs in explaining differences in equilibrium payoffs as well as in entry and exit timing. The analysis provides conditions under which the high-opportunity-cost firm enters first and gains a higher payoff.
\end{abstract}

Key words: Opportunity costs of assets, war of attrition, preemption, real options and industry dynamics.

\footnotetext{
- MEDS and Management \& Strategy Departments, Kellogg School of Management, Northwestern University. E-mail: franruiz@kellogg.northwestern.edu. I am very grateful to Sandeep Baliga, Anne Coughlan, Niko Matouschek and Jianjun Wu, as well as seminar participants at Northwestern, for helpful comments. I would also like to thank Daniel F. Spulber for his catching enthusiasm, insightful conversations, encouragement and support throughout this project.
} 


\section{INTRODUCTION}

Credibly reducing the set of available actions in the future can be beneficial for a firm competing in an imperfectly competitive industry. Such commitment to an aggressive or soft behavior if necessary may allow the firm to enjoy a variety of competitive advantages vis-à-vis other companies that have not been able to take such irrevocable actions. ${ }^{1}$ Indeed, resource commitment is a key explanation of superior performance. ${ }^{2}$ However, in an uncertain world, the desirability of commitment to certain courses of action is not very clear, especially if there exists a sufficiently high price to pay for failing to make a valuable commitment and/or the probability of such failure is relatively large. As a result, many strategic decisions under uncertainty are characterized by a tradeoff between the commitment to a particular course of action and the flexibility to respond to adverse states of the world.

In this paper, I analyze how the trade-off between commitment and flexibility is affected by differences in the opportunity costs of the assets involved. The existence of such costs is at the heart of the trade-off, ${ }^{3}$ but it has received little attention, if any. Differences in the opportunity costs of firms are likely to lead to distinct types of strategic behavior in terms of timing, accounting for the interplay between commitment and flexibility in a different manner. The game-theoretic real options literature (e.g., Dixit and Pindyck (1994)) provides the most adequate setting for such analysis, given its fully dynamic nature. This theory is basically devoted to analyzing how the existence of the "commitment-versus-flexibility" trade-off affects entry timing by duopolistic firms.

\footnotetext{
${ }^{1}$ See Dixit (1980), Ghemawat and Nalebuff (1985) or Judd (1985) for different examples.

${ }^{2}$ Shapiro $(1989$, p. 127) points out that the key to understanding business strategy arises from the timing of strategic decisions as well as the ability of firms to make commitments. See also Ghemawat (1991) for a detailed and rich discussion.

${ }^{3}$ Gilbert (1989, pp. 520-521).
} 
Basically, equilibrium timing takes into account incentives to wait for the arrival of new information and incentives to preempt the rival firm so as to delay its investment for some time or forever, which would allow the preemptor to make monopoly profits in the meantime. However, this literature has exclusively focused on investments that are entirely sunk for all players, so those that are partially irreversible are not studied at all. Despite their additional complexity, these situations are worthwhile examining, since they are probably the most relevant from a real-world viewpoint. For this reason, this paper presents a theoretical framework that addresses and explains the strategic patterns of investment and disinvestments based on differences in the opportunity costs of the assets used by firms.

In particular, I study a two-player game of timing under uncertainty. Firms differ only on the opportunity costs of the resources they possess, and thus their investments are not equally recoverable (for exogenous reasons not modeled in the paper). ${ }^{4} \mathrm{I}$ investigate the entry and exit behavior of both firms over the entire lifetime of an industry. The industry is assumed to expand up to a maturity date unknown to the firms, declining until it disappears thereafter. As a result, firms do not know ex ante the temporal evolution of their payoffs and thus have an incentive to delay entry in order to update their beliefs about the profitability of their (potential) investments. In principle, these incentives differ across firms in a complicated way because of asset differentiation. Therefore, I study the strategic implications of differences in the opportunity costs of assets across firms, abstracting away from other factors (such as product market competition), so as to have a

\footnotetext{
${ }^{4}$ One possible interpretation could be that firms have different skills in resource development, or access to different factor markets. Assets (or bundles of assets) are not allowed to be homogenous although they could be almost identical, so at least a minimal degree of factor differentiation, or firm-specific abilities in other usages of the assets is required.
} 
neat analysis of the trade-off between commitment and flexibility. More precisely, I focus on how differences in the value of outside options affect equilibrium payoffs as well as incentives to speed up entry and delay exit.

This paper contributes to the theory of timing games under uncertainty. These games are mostly applied to study incentives to make preemptive moves or to engage in wars of attrition. ${ }^{5}$ Influential applications of this continuous-time theory in a deterministic setting include topics such as market entry and/or exit. ${ }^{6}$ These timing games often have a stochastic counterpart, using real option models as the natural theoretical framework. ${ }^{7}$ The game presented here is the first to consider the interaction of partially irreversible entry and exit decisions in a stochastic setup with duopolistic firms.

The basic results of the model are as follows. Differences in the incentives to carry out a preemptive entry greatly depend on differences in the continuation payoff of firms in the exit subgames. This determines which firm has the (ex ante) advantage of caring less about uncertainty. On the one hand, the low-opportunity-cost firm only has the strategic advantage of being able to exit at its optimal monopoly date, unlike its competitor, so it can reap monopoly profits for some time. The latter is less committed to staying in declining the market and faces lower exit barriers, so it ends up exiting earlier

\footnotetext{
${ }^{5}$ Models of industry evolution in oligopolistic settings with uncertainty such as those by Ericson and Pakes (1995) or Amir and Lambson (2003) are significantly different. The main focus of these papers is on the properties of the long-run equilibrium. However, my model is a game of timing of (dis)investment, whereas this kind of literature do not consider timing competition (e.g., preemptive entry or exit in the form of a war of attrition) because of the assumption that there exist infinitely many potential entrants.

${ }^{6}$ Entry is studied by Fudenberg and Tirole (1985) or Dutta, Lach and Rustichini (1995), while the papers by Ghemawat and Nalebuff (1985) or Fudenberg and Tirole (1986) are devoted to exit. Londregan (1990) analyzes both entry and exit decisions in a duopoly.

${ }^{7}$ Dixit and Pindyck (1994, Ch. 9) present a duopoly model of entry under uncertainty. In turn, Lambrecht (2001) and Murto (2003) are dedicated to the analysis of exit decisions when profit evolution is stochastic for the two established firms. Despite Lambrecht's main focus is on the role of debt financing on explaining exit decisions, he also examines the entry decision of one of the firms when the other is already present in the market. As a result, he does not study the preemption game that would take place when neither has entered.
} 
when both are active in the industry. ${ }^{8}$ On the other hand, in the absence of product market advantages to either company, the high-opportunity-cost firm has three forces that benefit it and induce it to preempt its competitor. In the first place, it gets a more valuable outside option than its counterpart when exiting. In the second place, it gets such value earlier. In the third and last place, by entering first, the high-opportunity-cost firm could monopolize the market throughout its remaining lifetime for realizations of the maturity date that were not large enough so as to allow its competitor's entry. As a result, it may end up exiting later than it would if the market were duopolistic, unlike its rival. In this sense, the low-opportunity-cost firm's credible commitment to a later exit at its monopoly exit time is a two-edged sword, since it may simultaneously create incentives for the high-opportunity-cost firm to preempt it earlier.

Based on the previous discussion, the model predicts that the high-opportunitycost firm is the first one in committing resources (and gains a higher payoff) if the condition that its opportunity cost is above a critical value is satisfied. The reason is that the force benefiting the low-opportunity-cost firm is completely offset by the first two that benefit the high-opportunity cost firm. This, together with the third force mentioned above, allow the high-opportunity cost firm to preempt its rival. For example, this holds when one firm's investment is almost fully recoverable and its rival's investment is almost fully non-recoverable. The same condition is not only sufficient but also necessary when assets are almost identical in their opportunity cost. The point is that in this situation only the second force that favors the high-opportunity-cost firm is present, which means that it would prefer not delaying exit too long so as to prevent its outside

\footnotetext{
${ }^{8}$ See Ghemawat and Nalebuff (1985) for a similar result in a declining industry with capacity constraints.
} 
option from losing too much value. The firm can only do that when the opportunity cost is sufficiently high.

Previous work on the topic of "commitment-versus-flexibility" (e.g., Appelbaum and Lim (1985) and Spencer and Brander (1992)) has examined two-stage games in which one firm can either precommit its output before uncertainty is realized, or wait for the resolution of uncertainty. If the firm chooses to latter option, then it completely foregoes its opportunity to commit, and competes with its rival/s as an equal, but enjoys the informational benefits of flexibility. After comparing the (expected) payoffs to committing and to staying flexible, they conclude that the degree of uncertainty is negatively related to the desire to commit. Apart from the different questions addressed, these papers exogenously give a timing advantage to one of the firms, while another firm (or group of firms) is assumed to be passive in the sense that it cannot choose when to invest. The real options literature relaxes this "passiveness" and allows both duopolists to invest at any time they wish. However, it has mainly focused on either entry (e.g., Dixit and Pindyck (1994)) or exit (Lambrecht (2001) and Murto (2003)). Dixit (1989) examines both entry and exit for the monopoly case, so my analysis is the game-theoretic extension of such work, although I depart from the traditional real options framework and present a simpler and more tractable model. Finally, the current paper may also be considered an extension of Londregan's (1990) industry life cycle analysis when the cycle is unknown to both firms.

The organization of the paper is as follows. Section 2 describes the elements of the game in consideration, and the solution concept. Section 3 examines entry and exit 
patterns in a declining industry, while Section 4 is dedicated to a growing industry.

Section 5 draws empirical implications and sketches out avenues for further research.

\section{DESCRIPTION OF THE GAME AND SOLUTION CONCEPT}

Let time, denoted by $t$, be a continuous variable on $[0, \infty)$. At date 0 , two firms have to decide their entry and exit behavior throughout the entire lifetime of a certain industry. In particular, the profits that each firm would make if active are assumed to grow from date 0 onwards, until the industry begins to decline at a date $\widetilde{\tau}$ that is initially unknown to both firms. Once $\tilde{\tau}$ is realized, it becomes common knowledge, and from such date on, profits gradually decrease over time. ${ }^{9}$ Formally:

Assumption 1: For each realization $\tau$ of the random variable $\tilde{\tau}$, instantaneous profit made by a single firm if $m$ firms $(m=1,2)$ are operating in the market at date $t$ is as follows:

$$
\Pi_{m}(t, \tau)=\left\{\begin{array}{ll}
G_{m}(t) & \text { if } 0 \leq t \leq \tau \\
D_{m}(t-\tau) & \text { if } t>\tau
\end{array},\right.
$$

where $G_{1}(\cdot)>G_{2}(\cdot), D_{1}(\cdot)>D_{2}(\cdot), G_{2}(0)>0$ and $D_{2}(0)>0$. Furthermore, $G_{m}(\cdot)$ and $D_{m}(\cdot)$ are continuously differentiable functions $\forall m$, with positive and negative slopes, respectively. Finally, let $\lim _{t \rightarrow \infty} D_{m}(t-\tau)=0(m=1,2)$ to guarantee that the only reason why a firm would exit the market is the existence of opportunity costs.

Note that there can be a drastic increase/reduction in the flow of profits when $\tilde{\tau}$ occurs. The role of this assumption (together with Assumption 3 below) is to prevent

\footnotetext{
${ }^{9}$ This way of modeling industry evolution has become standard in this type of literature (see, e.g., Fudenberg and Tirole (1986) or Londregan (1990)). Such temporal evolution of profits may originate from a similar evolution of demand, given the empirical evidence on the positive profits-growth relationship. See Bradburd and Caves (1982) for more details.
} 
firms from entering a declining industry no matter what $\widetilde{\tau}$ is. In addition, let us also assume that $G_{1}(0) \leq D_{1}(0)$ to rule out corner solutions. ${ }^{10}$ Hence, initial conditions are adverse even for a monopolist.

Regarding the properties of the random maturity date, I assume the following:

Assumption 2: The instant of maturity of the market $\widetilde{\tau}$ is an exponential random variable.

Thus, the density function of $\widetilde{\tau}$ is $f(\tau)=\lambda e^{-\lambda \tau}$ for $\tau>0$ and $f(\tau)=0$ for $\tau \leq 0$, where $\lambda>0$ is the hazard rate.

In addition, potential entrants are assumed to be risk-neutral and discount future payoffs at the risk-free rate $r>0$. Entry into the market requires an upfront cost, so waiting allows firms to update their beliefs about the payoff they get (by the previous assumptions), and there is an option value to delaying entry:

Assumption 3: Potential entrants incur an investment cost $K \geq \frac{D_{1}(0)}{r}$ when entering the market.

The entry cost is assumed to be the same in order to make firms identical but for the opportunity costs of their assets. Further, $K$ is assumed to be large enough so as to rule out incentives to enter the industry when it is declining, irrespective of the number of firms present in the market at that point or not. Finally, as mentioned earlier, the entry cost is considered to be a partially non-recoverable cost. Thus, its irreversibility effect is mitigated by the fact that the investment of either firm could be employed in an alternative usage. In particular, we have:

\footnotetext{
${ }^{10}$ Otherwise, the equilibrium outcome of the game would be characterized by the high-opportunity-cost firm entering at 0 and its rival entering at its optimal entry time as a follower. See Section 4 for details.
} 
Assumption 4: Investments are partly recoverable once undertaken and entail an opportunity cost of $0<S_{1}<S_{2}<K$.

Hence, firm 2 bears a higher opportunity cost than firm 1, with $S_{2}<K$ to avoid "money pumps". Assumptions 1 and 4 imply that the model is not characterized by firstmover or second-mover advantages materialized in the product market interaction, or in the preemptive acquisition of scarce resources. Thus, the first entrant has the cost advantage of already committed resources, unlike its rival. Undertaking such preemptive action may be risky, but it would allow the incumbent to garner monopoly profits with entry blockaded for some time or forever. ${ }^{11}$ As a result, the only source of strategic behavior in this model arises from the timing of (different kinds of) investment. In addition, it is worth mentioning that, despite $S_{i}(i=1,2)$, and $K$ are exogenous, sunk costs are endogenous insofar they depend on the entry and exit times of firm $i$, which in turn depend on its rival's behavior.

We also make a technical assumption so as to bound firms' (expected) values. In particular, both $G_{1}(\cdot)$ and $G_{2}(\cdot)$ are unbounded, with the following restriction:

Assumption 5: $\int_{0}^{\infty} G_{1}(t) e^{-(r+\lambda) t} d t<\infty$

Lastly, to avoid coordination failures arising from simultaneous moves in continuous-time games, as discussed and analyzed in Fudenberg and Tirole (1985), we follow Dutta, Lach and Rustichini (1995) and assume the following:

Assumption 6: If both firms attempt to enter at some date $t$, then only one of them succeeds in doing so. The probability of firm 1 entering is $p \in(0,1)$.

\footnotetext{
${ }^{11}$ Provided continued operation after entry by the competitor were credible. This is an equilibrium feature of the model.
} 
In Fudenberg and Tirole (1985), $p$ is endogenously determined and, furthermore, is a function of time. For this reason, it is worth noting that our results do not depend on the specific value of $p$ whatsoever.

Given this setup, we will use the (pure-strategy) subgame perfect equilibrium solution concept. Letting $A=\{\mathrm{In}$, Out $\}$ be the action set of any firm at any date, firm $i$ 's (closed-loop) strategy is a family of functions $T_{i}^{t}$ as follows: $T_{i}^{t}: H_{t} \rightarrow A$. Hence, firm $i$ 's pure strategy assigns a date- $t$ action, "In" or "Out", to every conceivable history of the game $H_{t} \forall t \in[0, \infty) . H_{t}$ is commonly known and consists of all the actions taken by both firms before date $t$, as well as a left-continuous function $h_{t}:[0, t] \rightarrow\{0,1\}$, where 1 and 0 respectively represent whether or not $\widetilde{\tau}$ has been revealed to the firm at some $s \in[0, t]$. Due to the complexity of the strategy spaces, the exposition will largely focus on the equilibrium path of the game (given a realization of $\tilde{\tau}$ ), rather than the firms' equilibrium strategies.

\section{DECLINING INDUSTRY: ENTRY AND EXIT PATTERNS}

This section is dedicated to analyzing the patterns of entry and exit of firms when the industry is decaying and thus instantaneous profit has begun to decrease. Since maturity has occurred, firms have complete information. With both firms active and reentry allowed, this situation is somewhat similar to the one examined by Londregan (1990) on his extension of Ghemawat's and Nalebuff's (1985) seminal paper on exit from declining industries. In our case, however, it is the existence of opportunity costs of the assets used for operation in the market that induces incumbents to exit the industry. Also, there exists 
a continuum of states of the world, each corresponding to a different realization of $\widetilde{\tau}$, so we have to characterize the patterns of behavior that emerge for distinct maturity dates.

In order to solve the exit (sub)games, it is convenient to introduce the following function:

$$
E_{i}\left(t^{\prime} \mid t, m, \tau\right)=\int_{t}^{t^{\prime}} D_{m}(s-\tau) e^{-r s} d s+S_{i} e^{-r t^{\prime}}
$$

This function is parameterized by its last three arguments and represents firm $i$ 's continuation payoff when it operates from the current date $t$ until the future shut-down date $t^{\prime}$ in a declining industry with $m$ firms and state of the world $\tau$. It can be shown to be strictly quasi-concave, ${ }^{13}$ with its global maximum attained at

$$
\underset{t^{\prime} \geq t}{\arg \max } E_{i}\left(t^{\prime} \mid t, m, \tau\right)=\max \left(t, \max \left(\tau, \tau+D_{m}^{-1}\left(r S_{i}\right)\right)\right)
$$

To ease notation, let $\quad t_{i}^{x}(m, \tau) \equiv \tau+D_{m}^{-1}\left(r S_{i}\right) . \quad$ By Assumption $\quad 4$, $t_{2}^{x}(m, \tau)<t_{1}^{x}(m, \tau) \forall m=1,2$. Also, note that $t_{i}^{x}(m, \tau)$ could be greater or smaller than $\tau$, although, unless otherwise stated, we assume that $t_{2}^{x}(2, \tau)>\tau .{ }^{14}$

Given (1), it is clear that immediate exit is a dominant strategy for firm $i$ for all $t \geq t_{i}^{x}(1, \tau) \cdot{ }^{15}$ Based on this simple result, we now analyze the outcome of the equilibrium strategies for subgames starting at time $t_{2}^{x}(2, \tau) \leq t<\max \left(t_{1}^{x}(2, \tau), t_{2}^{x}(1, \tau)\right)$ (all proofs are in the appendix):

\footnotetext{
${ }^{12}$ Throughout the paper, we will consider all payoffs to be discounted to the initial date, which, of course, entails no loss of generality.

13 This follows because $\frac{\partial E_{i}\left(t^{\prime} \mid t, m, \tau\right)}{\partial t^{\prime}}=0 \Rightarrow \frac{\partial^{2} E_{i}\left(t^{\prime} \mid t, m, \tau\right)}{\partial t^{\prime 2}}<0$ if the function is not monotone decreasing.

${ }^{14}$ If this were not the case, it is straightforward to show that (at least) firm 2 would immediately exit at $\tau$ by the same reasoning that leads to Proposition 1 below.

${ }^{15}$ Strictly speaking, $t$ should be a function of $\tau$.
} 
Proposition 1: If the low-opportunity-cost firm is active at $t_{2}^{x}(2, \tau) \leq t<\max \left(t_{1}^{x}(2, \tau), t_{2}^{x}(1, \tau)\right), \quad$ or $\quad E_{1}\left(t_{1}^{x}(1, \tau) \mid t, 1, \tau\right) \geq K e^{-r t}$, then it is the only incumbent between $t$ and $t_{1}^{x}(1, \tau)>t$. Otherwise, it remains out of the market after $t$. The high-opportunity-cost firm is inactive past $t$ unless its rival is inactive past $t$, and, either firm 2 is already active at $t$, or $E_{2}\left(t_{2}^{x}(1, \tau) \mid t, 1, \tau\right) \geq K e^{-r t}$, in which case it monopolizes the market until $t_{2}^{x}(1, \tau)$.

In order to understand the outcome of the exit game played by both firms (if they are active), it is convenient to think of the continuation payoffs associated to the subgame as consisting of two elements. On the one hand, there exists an evenly shared prize (namely, the future flow of profits to be garnered by both firms) and, on the other, a proprietary outside prize (i.e., the opportunity cost, which is a stock) that differs across firms and thus explains the result. In particular, both opportunity costs decrease over time, but the value of the outside option decreases faster for firm 2, which increases its incentives to stop and get it earlier compared to its rival. For this reason, firm 1 has an advantage over firm 2 since only the former can credibly threaten to trigger a war of attrition at any date and win it. Hence, it is optimal for firm 2 -the equivalent to the large firm in the Ghemawat-Nalebuff model- not to even engage in a war of attrition it knows it would eventually lose and thereby it exits at $t_{2}^{x}(2, \tau)$. As a result, the low-opportunitycost firm faces higher exit barriers due to the extra commitment it enjoys, which increases its incentives to stay in the industry. The situation analyzed is an example of the well-known phenomenon that the first firm able to commit credibly to continued operation even under the pessimistic assumption of continued competition can force its rival to exit (Ghemawat and Nalebuff, 1985, p. 185). 
Continued operation is clearly a dominant strategy for any incumbent $\forall t \in\left[\tau, t_{2}^{x}(2, \tau)\right)$, no matter whether its competitor is active or not, as stems from (1). Together with Proposition 1, this completely characterizes the exit behavior of both firms when the industry is declining, so let us now focus on entry into a decaying industry. We first examine the situations in which one firm is already active in the market, and the market begins to contract.

If firm 1 is already in the market when $\widetilde{\tau}$ is revealed, firm 2 's optimal action is to exit immediately if $t_{2}^{x}(2, \tau) \leq \tau$ (by (1)), so let us assume again that $t_{2}^{x}(2, \tau)>\tau$. By Proposition 1, the high-opportunity-cost firm solves the following program:

$$
\max _{t \in\left[\tau, t_{2}^{x}(2, \tau)\right)} P V_{2}(t)=\int_{t}^{t_{2}^{t}(2, \tau)} D_{2}(s-\tau) e^{-r s} d s+S_{2} e^{-r t_{2}^{t}(2, \tau)}-K e^{-r t},
$$

provided that $P V_{2}(t) \geq 0$ because of the option to remain out. Yet, it can be shown that this condition does not hold, so remaining inactive forever is preferred to entry at any future date:

Lemma 1: $P V_{2}(t)<0 \forall t \in\left[\tau, t_{2}^{x}(2, \tau)\right)$.

If a firm waits to enter a declining industry, then it saves part of the entry cost. At the same time, it foregoes a certain profit flow. It is a fairly general conclusion in this model that a firm will either enter immediately or will remain inactive forever, due to the 
quasi-convexity of $P V_{2}(\cdot) .{ }^{16}$ In this case (see dashed curve in Figure 1), the size of $K$ is sufficiently large so as to make the first option unprofitable, which explains the result.

\section{FIGURE 1 ABOUT HERE}

In turn, if firm 2 is the only firm active in the market when maturity at $\tau$ is reached, then firm 1 could either enter before or after firm 2 has exited the market (again, we rule out trivial cases so that $\left.t_{2}^{x}(2, \tau)>\tau\right) .{ }^{17}$ It is straightforward to show that firm 1 would prefer to enter at $t_{2}^{x}(2, \tau)$ rather than at $t_{2}^{x}(1, \tau)$. Hence, firm 1 has to solve the following program subject to the constraint that remaining out of the industry, which yields a zero payoff, is less profitable:

$$
\max _{t \in\left[\tau, t_{1}^{x}(1, \tau)\right)} P V_{1}(t)= \begin{cases}\int_{t}^{t} D_{2}^{t}(2, \tau) & \\ t_{1}^{(}(1, \tau) & \text { if } t \in\left[\tau, t_{2}^{x}(2, \tau)\right) \\ \int_{t_{2}^{t}(2, \tau)} D_{1}(s-\tau) e^{-r s} d s+S_{1} e^{-r t_{1}^{t}(1, \tau)}-K e^{-r t} d s & \text { if } t \in\left[t_{2}^{x}(2, \tau), t_{1}^{x}(1, \tau)\right) \\ \int_{t}^{t}(1, \tau) & \end{cases}
$$

Again, it can be shown that it is optimal to be inactive, as stems from the graphical situation represented by the solid curve in Figure 1:

Lemma 2: $P V_{1}(t)<0 \forall t \in\left[\tau, t_{1}^{x}(1, \tau)\right)$.

\footnotetext{
16 For example, the same kind of result would obtain by maximizing $\int_{t}^{t_{2}^{x}(2, \tau)} D_{2}(s, \tau) e^{-r s} d s+S_{2} e^{-r t_{2}^{x}(2, \tau)}-K e^{-r t}$, where $D_{2}(s, \tau)$ (firm $i$ 's duopoly profit at date $s$ when the industry begins its decline at $\tau$ ) is a continuously differentiable function with $\frac{\partial D_{2}(s, \tau)}{\partial s}<0$.

${ }^{17}$ If $t_{2}^{x}(2, \tau) \leq \tau$, then the same steps followed when analyzing firm 2's problem yield the same result (now using the fact that $\left.\frac{D_{1}(0)}{r} \leq K\right)$.
} 
On the other hand, it remains to study the situations in which no firm is active in an expanding industry and suddenly the contracting stage starts at state $\tau$. Given that neither firm has incentives to enter even as an undisputed monopolist, ${ }^{18}$ entry into a declining industry will never take place. As in the duopoly case, the result is driven by Assumption 3, which determines the size of $K .{ }^{19}$ The following proposition summarizes all the results of this section:

Proposition 2: The outcome associated to a subgame perfect equilibrium has the following features during the decline stage of an industry: no firm enters when the industry is contracting, no matter how many firms are active at any date; if only firm $i$ is active at $\tau$, then it exits at $\max \left(\tau, t_{i}^{x}(1, \tau)\right)$; lastly, if both are operating at $\tau$, then firm $i$ exits at $\max \left(\tau, t_{i}^{x}(i, \tau)\right)(i=1,2)$.

\section{GROWING INDUSTRY: ENTRY AND EXIT PATTERNS}

It seems intuitive that incumbents are not willing to exit from expanding markets when technologies are invariant over time and are known to yield positive operating profits no matter what. Indeed, in this model, exit from a growing industry never takes place, despite the presence of uncertainty about the future growth of the market. The main point

$18 \int_{t}^{t_{i}^{x}(1, \tau)} D_{1}(s-\tau) e^{-r s} d s+S_{i} e^{-r t_{i}^{x}(1, \tau)}-K e^{-r t}$ is strictly quasi-convex on $(0, \infty)(i=1,2)$ and attains an interior minimum at $\tau+D_{1}^{-1}(r K)<\tau$, so it is a monotone increasing function on $\left[\tau, t_{i}^{x}(1, \tau)\right)$. Because $\int_{t_{i}^{x}(1, \tau)}^{t_{i}^{x}(1, \tau)} D_{1}(s-\tau) e^{-r s} d s+S_{i} e^{-r t_{i}^{x}(1, \tau)}-K e^{-r t_{i}^{x}(1, \tau)}<0$, no entry is preferred to entry at any $t \in\left[\tau, t_{i}^{x}(1, \tau)\right)$.

${ }^{19}$ Were the entry cost to be lower, a preemption game might be played by both firms. Given this new setup, it can be shown that the equilibrium outcome of the preemption game would be characterized by both firms entering immediately at $\tau$. Quasi-convexity would play an important role again. If there were room only for one of them, then the extra commitment enjoyed by the low-opportunity-cost firm would allow it to preempt its rival and thus prevent its entry forever. 
is that, if a firm is willing to enter the industry, why should it change its mind if the market keeps on growing and the (instantaneous) probability of decline faced at any subsequent date was known even before the entry time? The proof of this result is much more easily demonstrated once we have introduced some new notation. For this motive, let us assume for the moment that all subgames following entry by at least one firm are characterized by no firm exiting while the industry still grows. The last proposition of the paper shows that this is indeed the case. Also, throughout all this section, we use the following redefinition for notational convenience: $t_{i}^{x}(m, \tau) \equiv \max \left(\tau, \tau+D_{m}^{-1}\left(r S_{i}\right)\right)$.

Let us first examine subgames in which the realization of $\widetilde{\tau}$ is not known, and one of the firms is already present in the market. Since active firms exit the market only if it is decaying, firm 1's payoff as a follower when it enters at date $t$ is:

$$
V_{1}^{f}(t)=\left[\bar{E}_{t}\left(\int_{t}^{t_{2}^{x}(2, \tau)} \Pi_{2}(s, \tau) e^{-r s} d s+\int_{t_{2}^{t}(2, \tau)}^{t_{1}^{x}(1, \tau)} \Pi_{1}(s, \tau) e^{-r s} d s+S_{1} e^{-r t_{1}^{x}(1, \tau)}\right)-K e^{-r t}\right] \operatorname{Pr}(t<\tau),
$$

where $\bar{E}_{t}(\cdot)$ denotes the expectation operator conditional upon information at date $t$. If firm 1 enters at $t$, then it incurs the entry cost in return for an expected payoff, with the expectation conditional upon available information at the time of entry. The payoff to the firm depends on its optimal exit time (as well as that of its competitor), which is a random variable insofar it is contingent on future market evolution. Also, note that the firm seizes the described net expected payoff only if the industry is growing. ${ }^{20}$ The probability that this event occurs is precisely $\operatorname{Pr}(t<\tau)$.

Similarly, firm 2's payoff when it enters as a duopolist at date $t$ is:

\footnotetext{
${ }^{20}$ There is a term missing in $V_{1}^{f}(t)$ which would refer to the payoff expected by firm 1 if the maturity of the market occurred at some time before $t$. By Proposition 2, no firm would be willing to enter a declining market, so this term is zero and thus has not been included.
} 


$$
V_{2}^{f}(t)=\left[\bar{E}_{t}\left(\int_{t}^{t_{2}^{x}(2, \tau)} \Pi_{2}(s, \tau) e^{-r s} d s+S_{2} e^{-r t_{2}^{x}(2, \tau)}\right)-K e^{-r t}\right] \operatorname{Pr}(t<\tau)
$$

If both firms were to enter as followers, it may appear that, a priori, the highopportunity-cost firm should care less about risk and invest earlier that its competitor, given its higher outside value. This need not be true, however, because a more valuable outside option has a negative strategic effect when deciding the time to exit. Ex ante, firms also care about the profits they can make when the industry is declining, and in a duopoly situation, the low-opportunity-cost firm has an advantage over its rival no matter what the realization of $\widetilde{\tau}$ is. This creates incentives to speed up entry relative to the highopportunity-cost firm. Firm 1 has more incentives than firm 2 if and only if it expects to gain more, namely if the following holds:

$$
\int_{\max \left(0, D_{2}^{-1}\left(r S_{2}\right)\right)}^{\max \left(0, D_{1}^{-1}\left(r S_{1}\right)\right)} D_{1}(s) e^{-r s} d S+S_{1} \min \left(1, e^{-r D_{1}^{-1}\left(r S_{1}\right)}\right)-S_{2} \min \left(1, e^{-r D_{2}^{-1}\left(r S_{2}\right)}\right)>0
$$

Expression (2) represents the net effect of the trade-off faced by both firms due to the nature of their investments. ${ }^{21}$ A larger opportunity cost implies a more valuable outside option as well as seizing it sooner. ${ }^{22}$ However, earlier exit also allows the rival firm to reap a stream of monopoly profits. If the condition holds, then firm 1 expects to gain

\footnotetext{
${ }^{21}$ The difference in the continuation payoffs of the firms when the industry is declining is positive for firm 1 if $\int_{t_{2}^{x}(2, \tau)}^{t_{1}^{x}(1, \tau)} D_{1}(s-\tau) e^{-r s} d s+S_{1} e^{-r t_{1}^{x}(1, \tau)}-S_{2} e^{-r t_{2}^{x}(2, \tau)}>0$. Making a change of variables, straightforward manipulations yield $\int_{\max \left(0, D_{2}^{-1}\left(r S_{2}\right)\right.}^{\max \left(0, D_{1}^{-1}\left(r S_{1}\right)\right)} D_{1}(s) e^{-r s} d s+S_{1} e^{-r \max \left(0, D_{1}^{-1}\left(r S_{1}\right)\right)}-S_{2} e^{-r \max \left(0, D_{2}^{-1}\left(r S_{2}\right)\right)}>0, \quad$ whence immediately follows.

${ }^{22}$ The favorable effect of these two forces for firm 2 can be seen after a simple operation:

$$
\begin{aligned}
& S_{1} \min \left(1, e^{-r D_{1}^{-1}\left(r S_{1}\right)}\right)-S_{1} \min \left(1, e^{-r D_{2}^{-1}\left(r S_{2}\right)}\right)= \\
& -\left(S_{2}-S_{1}\right) \min \left(1, e^{-r D_{2}^{-1}\left(r S_{2}\right)}\right)-S_{1}\left(\min \left(1, e^{-r D_{2}^{-1}\left(r S_{2}\right)}\right)-\min \left(1, e^{-r D_{1}^{-1}\left(r S_{1}\right)}\right)\right)<0 .
\end{aligned}
$$
}


relatively more than firm 2 from the entry date $t$ onwards, which stimulates an earlier entry as a follower. The following lemma mainly deals with the impact of (2) on entry timing, as well as with some relevant properties of $V_{i}^{f}(t)$ :

Lemma 3: $V_{i}^{f}(t)$ is a function with a unique global maximizer $t_{i}^{f}>0$ such that $V_{i}^{f}(t)>0 \forall t \geq t_{i}^{f}, i=1,2$. Also, $t_{1}^{f}<t_{2}^{f}$ if and only if (2) is satisfied if and only if $V_{1}^{f}(t)>V_{2}^{f}(t)$

Remark 1: $t_{2}^{f}$ is such that the marginal cost of waiting (profit flow foregone) equals the marginal value of delaying entry. The latter depends on both sunk cost saved by deferring investment and losses, if any, that firm 2 expects it would avoid by waiting if the industry suddenly started decaying:

$$
G_{2}\left(t_{2}^{f}\right) d t=r K d t+\max \left(K-\int_{t_{2}^{f}}^{t_{2}^{x}\left(2, t_{2}^{f}\right)} D_{2}\left(s-t_{2}^{f}\right) e^{-r\left(s-t_{2}^{f}\right)} d s-S_{2} e^{-r\left[t_{2}^{x}\left(2, t_{2}^{f}\right)-t_{2}^{f}\right]}, 0\right) \lambda d t .{ }^{23}
$$

To determine which firm enters in the first place if none has entered, we need to identify first the payoff structure when the roles of each firm (either leader or follower) are exogenously preassigned. Then both firms could compare the payoff to leading and following and thus decide on the role they want to assume, given the expected behavior of their corresponding rival. This endogenizes the role of each firm.

We first proceed to identify such payoff structure. Thus, firm $i$ 's problem as a follower if its rival entered in the first place at some date $t$ is:

$$
\begin{aligned}
& \max _{t_{i} \geq t} V_{i}^{f}\left(t_{i}\right) \\
& \text { s.t. } V_{i}^{f}\left(t_{i}\right) \geq 0
\end{aligned}
$$

\footnotetext{
${ }^{23}$ Of course, firm 1's problem could be given a similar marginal interpretation.
} 
In consequence, firm $i$ 's best-response is to enter at $\max \left(t, t_{i}^{f}\right)$ by Lemma 3 (note that $\left.V_{i}^{f}\left(\max \left(t, t_{i}^{f}\right)\right) \geq 0\right)$, which implies that the payoff of firm 1 when it leads and firm 2 follows in an optimal fashion is:

$$
V_{1}^{l}(t)= \begin{cases}\int_{t}^{t_{2}^{f}} f(\tau)\left(\int_{t}^{\tau} G_{1}(s) e^{-r s} d s+\int_{\tau}^{t_{1}^{x}(1, \tau)} D_{1}(s-\tau) e^{-r s} d s+S_{1} e^{-r t_{1}^{x}(1, \tau)}\right) d \tau+ & \\ \int_{t_{2}^{f}}^{\infty} f(\tau)\left(\int_{t}^{t_{2}^{f}} G_{1}(s) e^{-r s} d s+\int_{t_{2}^{f}}^{\tau} G_{2}(s) e^{-r s} d s+\int_{\tau}^{t_{2}^{x}(2, \tau)} D_{1}(s-\tau) e^{-r s} d s+\right. & \\ \left.\int_{t_{1}^{x}(1, \tau)} D_{1}(s-\tau) e^{-r s} d s+S_{1} e^{-r t_{l}^{x}(1, \tau)}\right) d \tau-K e^{-r t} \int_{t}^{\infty} f(\tau) d \tau & \text { if } 0 \leq t \leq t_{2}^{f} \\ t_{2}^{t}(2, \tau) & \text { if } t>t_{2}^{f} \\ V_{1}^{f}(t) & \end{cases}
$$

Note that $V_{1}^{l}(t)$ is non-differentiable although it is continuous at $t_{2}^{f}$. In turn, $V_{2}^{l}(t)$ is constructed in a similar way:

$$
V_{2}^{l}(t)= \begin{cases}\int_{t}^{t_{1}^{f}} f(\tau)\left(\int_{t}^{\tau} G_{1}(s) e^{-r s} d s+\int_{\tau}^{t_{2}^{t}(1, \tau)} D_{1}(s-\tau) e^{-r s} d s+S_{2} e^{-r t_{2}^{x}(1, \tau)}\right) d \tau+ & \\ \int_{t_{1}^{f}}^{\infty} f(\tau)\left(\int_{t}^{t_{1}^{f}} G_{1}(s) e^{-r s} d s+\int_{t_{1}^{f}}^{\tau} G_{2}(s) e^{-r s} d s+\int_{\tau}^{t_{2}^{x}(2, \tau)} D_{2}(s-\tau) e^{-r s} d s+\right. & \\ \left.S_{2} e^{-r t_{2}^{t}(2, \tau)}\right) d \tau-K e^{-r t} \int_{t}^{\infty} f(\tau) d \tau & \text { if } 0 \leq t \leq t_{1}^{f} \\ V_{2}^{f}(t) & \text { if } t>t_{1}^{f}\end{cases}
$$

First-movers perceive that potential entrants may take a fixed part of the industry profit stream with certain probability, so prospective future competition has no marginal effect on payoffs, and thus $V_{i}^{l}(t)$ has somewhat similar properties to its counterpart $V_{i}^{f}(t)$ :

Lemma 4: $V_{1}^{l}(t)$ is a function with a unique global maximizer $\hat{t}_{1} \in\left\{t_{1}^{l}, t_{1}^{f}\right\}$ (with $t_{1}^{l}>0$ if it exists) such that $V_{1}^{l}(t)>0 \forall t \geq \hat{t}_{1} . V_{2}^{l}(t)$ is a function with a unique global 
maximizer $t_{2}^{l}>0$ such that $V_{2}^{l}(t)>0 \forall t \geq t_{2}^{l}$. Also, $t_{2}^{l}<t_{2}^{f}$ and $t_{2}^{l}<t_{1}^{l}<t_{1}^{f}$ (whenever $\left.\hat{t}_{1}=t_{1}^{l}\right)$

There are a few aspects that are worthwhile discussing. In the first place, we have $t_{2}^{l}>0$ even though $S_{2} \rightarrow K$. Hence, discounting (and the fact that the industry is initially not very attractive) introduces a certain degree of irreversibility in the entry decision. Firm 2 may invest $K$ and recoup $S_{2} e^{-r t} \approx K e^{-r t}$ at the time of exit, thereby risking to losing part of its entry cost: (approximately) $K\left(1-e^{-r t}\right)>0$. As a result, there is an option value of waiting even for a firm that cannot be preempted and whose assets are almost fully recoverable.

In the second place, if firms could enter at their optimal entry time as first-movers (namely, $\hat{t}_{1}$ and $t_{2}^{l}$ ), then firm 2 would enter earlier than firm 1 , even though the followers' responses were identical (i.e., $t_{1}^{f}=t_{2}^{f}$ ). This result is driven by the fact that future entry, which is contingent on the market still growing, has a fixed effect on the payoff of the first entrant, so the latter behaves as if it were to monopolize the market throughout its entire lifetime. Unlike the follower case (which crucially depends on the violation of (2)), it can be shown that the high-opportunity-cost firm always gains more than its rival during the decline phase if the industry were monopolized. As a result, it has more incentives to speed up entry as a leader. This is not in contradiction with the fact that firm 1 may enter earlier than firm 2 as a duopolist, since firm 1's exit behavior is unaffected by the presence of firm 2, while the converse need not be true: firm 2 exits at $t_{2}^{x}(2, \tau)$ or $t_{2}^{x}(1, \tau)$ depending on whether or not firm 1 is active during the decline phase. 
Thus far, we have treated the roles of first- and second-entrants as exogenous, and we have not considered incentives for preemptive entry. So endogenizing the roles of the firms constitutes the next step of the analysis. Taking into account the followers' bestresponses, let $L_{i}(t)$ denote the payoff to firm $i$ when it enters in the first place as a leader at date $t$. Similarly, let $F_{i}(t)$ denote firm $i$ 's payoff as a follower when its competitor has entered first at time $t$. Then, we have shown the following, for $i, j=1,2(i \neq j)$ :

$$
\begin{gathered}
L_{i}(t)= \begin{cases}V_{i}^{l}(t) & \text { if } t \in\left[0, t_{j}^{f}\right] \\
V_{i}^{f}(t) & \text { if } t \in\left(t_{j}^{f}, \infty\right)\end{cases} \\
F_{i}(t)= \begin{cases}V_{i}^{f}\left(t_{i}^{f}\right) & \text { if } t \in\left[0, t_{i}^{f}\right] \\
V_{i}^{f}(t) & \text { if } t \in\left(t_{i}^{f}, \infty\right)\end{cases}
\end{gathered}
$$

The consideration of the preemptive nature of certain types of equilibria requires the introduction of some new notation. So let us define $t_{i}^{*}=\inf \left\{t \in\left[0, t_{i}^{f}\right): L_{i}(t) \geq F_{i}\left(t_{i}^{f}\right)\right\}$, with $t_{i}^{*}=\infty$ if the infimum does not exist. Thus, $t_{i}^{*}$ is the first date at which preemptive entry by firm $i$ would become a credible threat, and for this reason, we call it firm $i$ 's credible threat date. Both firm $i$ and its rival know that no preemptive action can be undertaken by firm $i$ before $t_{i}^{*}$ because it lacks incentives, and thereby it prefers following rather than leading. ${ }^{24}$ To avoid a trivial outcome, we will assume that $t_{i}^{*}>0$ at least for some $i^{25}$ Based on Lemmas 3 and 4 , three possible equilibrium configurations are possible, each with its own features, depending on

\footnotetext{
${ }^{24}$ It is worth noting that there might be no incentives to preemptive entry at dates after $t_{i}^{*}$ because the payoff to being a leader might be smaller than that to being a follower.

${ }^{25}$ Otherwise, preemptive reasons would lead both firms to attempt to enter at date 0 , and Assumption 6 would deliver the result of the entry game played by both firms. However, note that the artificial nature of this assumption would affect the actual equilibrium, which would be in mixed strategies, and would involve a positive probability of simultaneous entry at 0 , ruled out by Assumption 6 .
} 
whether the parameter space is such that $t_{2}^{l}<t_{1}^{l}<t_{2}^{f}<t_{1}^{f}, \quad t_{2}^{l}<t_{1}^{l}<t_{1}^{f}<t_{2}^{f}$, or $t_{2}^{l}<t_{2}^{f}<t_{1}^{f}$. This yields a variety of different outcomes, although there are some general consistent conclusions that do not depend on the specific values of the parameters. Yet, we first show that there exists a unique equilibrium of the overall game no matter what the configuration of parameters is. As a matter of fact, it is worth noting that the equilibrium outcome is always characterized by the firm with the smallest credible threat date entering first and delaying entry until the last moment in which its rival cannot preempt it.

Proposition 3: The game has a unique subgame perfect equilibrium.

Now we can provide a sufficient condition under which the high-opportunity-cost firm gains a larger equilibrium payoff. It also implies that such firm enters first in equilibrium (provided the maturity date is sufficiently long) if that condition is satisfied:

Proposition 4: If (2) is violated, then the high-opportunity-cost firm gets a higher payoff than its rival and is expected to enter in the first place. In particular, the low-opportunitycost firm would enter at $t_{1}^{f}$ and the high-opportunity-cost firm at $\min \left(t_{2}^{l}, t_{1}^{*}\right)<t_{1}^{f}$.

This result follows because $L_{1}(t)-F_{1}\left(t_{1}^{f}\right)<L_{2}(t)-F_{2}\left(t_{2}^{f}\right) \forall t \in\left[0, t_{2}^{f}\right]$, so the gain from preemption at date $t, L_{i}(t)-F_{i}\left(t_{i}^{f}\right)$, is larger for firm 2 , and thus $t_{2}^{*}<t_{1}^{*}$ (see Figure 2; the dashed curves represent payoffs as a leader, while the solid curves represent payoffs as a follower). Firm 2 has more to lose if it is preempted because, if it entered first, it could monopolize the industry throughout its entire lifetime for certain states of the world, thus exiting later than it would if the industry were duopolistic. Further, firm 2's incentives to preempt are greater because it earns more than firm 1 during the decline phase even though the market is a duopoly. Overall, firm 2 ends up preempting firm 1 in 
equilibrium, but delaying entry until the very last moment at which firm 1's preemptive entry is not credible: $t_{1}^{*}$. Sometimes, it may even enter at its optimal entry time as a leader, if it is smaller than $t_{1}^{*}$ (see Figure 3).

\section{FIGURES 2 AND 3 ABOUT HERE}

Condition (2) is not met if $S_{2} \geq \frac{D_{1}(0)}{r},{ }^{26}$ so it suffices that firm 2's investment has an opportunity cost large enough. Consequently, when firm 1's investment is (almost) fully irreversible and firm 2's is (almost) fully reversible (i.e., $S_{1} \rightarrow 0$ and $S_{2} \rightarrow K$ ), $\begin{array}{lllll}\text { Proposition } & 4 & \text { applies. } & \text { Furthermore, } & \text { letting }\end{array}$ $Z \equiv \lambda\left(\int_{0}^{\infty} D_{1}(0) e^{-r s} d s-\int_{0}^{\infty} D_{1}(s) e^{-r s} d s\right) / \int_{0}^{\infty} D_{1}(0) e^{-r s} d s$, it can be shown that preemptive motives are not relevant under certain assumptions:

Proposition 5: Suppose that $S_{1} \rightarrow 0$ and $S_{2} \rightarrow K$. Then the high-opportunity-cost firm's equilibrium payoff is greater than its rival's. In addition, suppose that $G_{m}(t)=\pi(m) G(t)$, with $\pi(1)>\pi(2)>0$. Then the subgame perfect equilibrium outcome of the game is such that the high-opportunity-cost firm is expected to enter at $t_{2}^{l}$ and the low-opportunity-cost firm at $t_{1}^{f}$ if $\frac{\pi(1)-\pi(2)}{\pi(1)} \geq \frac{Z}{1+Z}$.

${ }^{26}$ If $S_{2} \geq \frac{D_{1}(0)}{r}>S_{1}$, then $S_{2} \geq \int_{0}^{D_{1}^{-1}\left(r S_{1}\right)} D_{1}(0) e^{-r s} d s+\frac{D_{1}(0)}{r} e^{-r D_{1}^{-1}\left(r S_{1}\right)}>\int_{0}^{D_{1}^{-1}\left(r S_{1}\right)} D_{1}(s) e^{-r s} d s+S_{1} e^{-r D_{1}^{-1}\left(r S_{1}\right)}$, which shows that (2) does not hold. This proof has made use of the facts that $D_{1}(\cdot)$ is decreasing and $S_{2} \geq \frac{D_{1}(0)}{r}>S_{1}$. The same kind of proof works for $S_{2}>S_{1} \geq \frac{D_{1}(0)}{r}$. 
Proposition 5 provides conditions under which firm 2 would enter at its optimal entry time as a leader, because firm 1 would never have enough incentives to preempt the former (i.e., $t_{1}^{*}=\infty$ ). If the percentage decrease in monopoly profits due to entry by another firm is sufficiently large, then entry by firm 2 when it follows is speeded up so much that it would immediately respond to firm 1's entry. Firm 1 would be deterred by firm 2's credible threat of immediate entry and would rather be a follower that at least does not suffer the consequences of competition to enter first (see Figure 3).

The high-opportunity-cost firm also preempts its competitor in a winner-takes-all setting. When only competition for being the first matters, perhaps due to extremely tough competition in the product market, firm 2 is the stronger firm, because it has more incentives to speed up entry. The point is that it expects to gain more than its rival, given the absence of strategic interaction when the industry is declining:

Proposition 6: Let $L_{1}(0) \leq 0$ and $G_{2}(\cdot) \rightarrow 0$ pointwise. ${ }^{27}$ Then the high-opportunity-cost is the only entrant and gains a positive payoff.

We now turn to the cases in which firms are almost identical (that is, $S_{1} \uparrow S_{2}$ ), so that $t_{1}^{1} \downarrow t_{2}^{1}$. Under certain assumptions, only two configurations are possible, $t_{2}^{l}<t_{1}^{l}<t_{1}^{f}<t_{2}^{f}$ or $t_{2}^{l}<t_{1}^{l}<t_{2}^{f}<t_{1}^{f}$, depending on whether expression (2) holds or not, which completely explains the result:

Proposition 7: Suppose that $D_{2}^{\prime \prime}(\cdot)>0$ and $D_{1}^{\prime}\left(D_{1}^{-1}(r S)\right)=D_{2}^{\prime}\left(D_{2}^{-1}(r S)\right) \forall S$, and let $S_{1} \uparrow S_{2}$. Then the low-opportunity-cost firm enters a growing market earlier than its rival

\footnotetext{
${ }^{27}$ If $L_{1}(0)>0$, the equilibrium would be in mixed strategies, with a positive probability of simultaneous entry at date 0 . Yet, it can be shown that firm 2 would play "in" with greater probability than firm 1 .
} 
if and only if $S_{2}<\frac{D_{1}(0)}{r}$, with first-movers always attaining the highest equilibrium payoff of both firms.

When firms are almost identical, differences in their behavior only depend on which firm is at an advantage or disadvantage when the market contracts (see e.g. Figure 4 for the case in which $\left.S_{2}<\frac{D_{1}(0)}{r}\right) .{ }^{28}$ In this particular case, firms weigh the benefit of getting a certain outside value at an early date versus garnering monopoly profits for some time and getting almost the same value at a later time. The proof of the proposition shows that the first situation is preferred if and only if the value is high relative to the profits the firm can reap, which drives the result.

\section{FIGURE 4 ABOUT HERE}

In particular, it can be shown that the previous proposition is a special case of the following one under certain assumptions:

Proposition 8: Let $G_{m}(t)=\pi(m) e^{\beta t}$ and $D_{m}(t-\tau)=\pi(m) e^{\alpha(\tau-t)}$, with $\min (\alpha, \beta)>0$. and assume that $\frac{\pi(1)-\pi(2)}{\pi(1)} \geq \frac{\alpha}{\alpha+r}$. Then there exists a continuous increasing function $Q\left(S_{1}\right)$ with $Q(0)=\frac{\pi(1)}{\alpha+r}>0$ which is strictly concave on $\left[0, \frac{\pi(1)}{r}\right)$ and linear on $\left[\frac{\pi(1)}{r}, K\right)$ such that (2) does not hold if and only if $S_{2} \geq Q\left(S_{1}\right)$.

\footnotetext{
${ }^{28}$ The role of the assumptions under which the proposition holds is to ensure that there exists a single threshold such that the region on which one type of firm is at an advantage over the other is connected. Examples of functions that satisfy the required properties are $D_{m}(s)=\frac{a \pi(m)}{b+\pi(m) s}$ (with $\pi(1)>\pi(2)$ and $\min (a, b)>0)$ or $D_{m}(s)=\pi(m) e^{-\alpha s}$, with $\alpha>0$.
} 
Hence, for $S_{2}<\frac{\pi(1)}{\alpha+r}$, (2) always holds, while, for larger $S_{2}$, there must be a significant difference between $S_{1}$ and $S_{2}$ so that (2) does not hold, up to a point at which just the fact that $S_{2}>S_{1}$ is enough to guarantee the violation of (2): if $S_{2} \geq \frac{\pi(1)}{r}$, then $S_{2} \geq Q\left(S_{1}\right)$ for $S_{1} \in\left[0, S_{2}\right)$ (so (2) does not hold and Proposition 4 applies). When (2) is violated, Proposition 4 implies that firm 2 enters first and gains a higher equilibrium payoff. In short, a necessary condition for firm 1 to gain more and enter earlier than its rival is that the difference in the opportunity costs of the assets should not be too big if $S_{2}$ is large. This requirement is automatically satisfied when $S_{2}$ is relatively small (see Figure 5).

\section{FIGURE 5 ABOUT HERE}

To conclude, it only remains to characterize the exit behavior of incumbents when $\tilde{\tau}$ is still unknown to them. As commented above, the facts that opportunity costs decrease over time because of discounting and the market is expected to grow imply that the following:

Proposition 9: In a subgame perfect equilibrium, no active firm exits the industry before it starts decaying.

\section{CONCLUSION}

This paper has focused on the entry and exit behavior of two firms throughout the entire lifetime of an industry. Both firms are assumed to be symmetric except for the opportunity cost of the assets they put in place when active in the market. The path 
associated to the unique subgame perfect equilibrium of the game has simple features. Any firm, if entering the market, bears uncertainty about the future maturity date of the industry and chooses not to exit while uncertainty is present. Once the maturity is realized, no potential entrant is willing to enter, while incumbents do exit. If both firms are active at the maturity date, then the high-opportunity-cost firm exits earlier than its rival, because the latter can credibly commit to continued operation even though the former threats to stay until its (monopoly) exit time. This shows that an exit barrier is a determinant weapon for winning a war of attrition in the context of a declining market.

In this paper, I have addressed the question of how the nature of resources and capabilities of competing firms affects their optimal and actual timing of entry. Thus, the role of differences in the opportunity costs of the assets employed by distinct firms as a determinant of entry order has been examined, which sheds a new light on the trade-off between commitment and flexibility. Despite the theoretical focus of the paper, I should emphasize that the model yields relevant empirical predictions regarding entry and exit timing of firms that employ assets with different opportunity costs. In particular, the analysis predicts that the firm with a higher opportunity cost asset has a tendency to enter first. The firm with lower opportunity cost can enter first, but only if the present value of the profit stream while the market is contracting is sufficiently large relative to that of its competitor. For certain functional forms, this holds if the high-opportunity-cost firm has an outside option that is not sufficiently valuable.

The model has some additional implications for the rapidly growing field of industry dynamics. In the first place, it seems desirable to incorporate firm-level 
innovation or analyze how entry and exit patterns would be affected by some correlation between market evolution and the temporal evolution of opportunity costs.

In the second place, it would be worthwhile examining the implications of timing competition such as the one described in this paper for the process of resource accumulation. In this setup, firms only decide about their entry and exit behavior, and cannot choose the nature of their investments. For some exogenous reason (e.g, differences in the capability to manufacture substitute products), firms pursue different kinds of investment. There are at least two ways of incorporating decisions about the nature of the investments. One is that, at the time of entry, firms can choose the opportunity cost of their investments, with the only restriction that the second-mover cannot choose the same degree chosen by the first-mover (although it could be arbitrarily close). In this case, competition for resources would probably enhance the incentives to preempt the rival. For example, suppose that one firm could get the maximal feasible payoff by entering at $t$ by acquiring an asset with opportunity cost $S .^{29}$ Then its rival could preempt it at $t-\varepsilon$ by purchasing a resource with a different opportunity cost, possibly higher. Of course, this would have an additional effect on the former firm's response as a follower (a pair consisting of the type of investment and a decision of whether or not to enter for each date), which may greatly complicate the analysis.

For this reason, a second, more limited but simpler, way of studying the same phenomenon would be to suppose that firms choose some idiosyncratic characteristics that will make them more or less keen to undertake a certain kind of investment. The decision would take place at a previous stage to the first date of potential entry into the market, and, if the new game were sequential, I conjecture that second-movers in this

\footnotetext{
${ }^{29} \mathrm{We}$ have seen that this was possible for certain values of the parameters.
} 
previous stage would be at an advantage and would preempt first-movers at the market game. 


\section{REFERENCES}

Amir, R. and Val E. Lambson (2003), "Entry, Exit, and Imperfect Competition in the Long Run”, Journal of Economic Theory, 110(1): 191-203.

Appelbaum, E. and Chin Lim (1985), "Contestable Markets under Uncertainty", Rand Journal of Economics 16(1): 28-40.

Boyer, M., Pierre Lasserre, Thomas Mariotti and Michel Moreaux (2001), "Real Options, Preemption, and the Dynamics of Industry Investments", working paper no. 20-10, Economics Department, UQAM.

Bradburd, R. M. and Richard E. Caves (1982), “A Closer Look at the Effect of Market Growth on Industries' Profits", Review of Economics and Statistics, 64(4): 635-645.

Dixit, A. K. (1980), "The Role of Investment in Entry Deterrence", Economic Journal 90(357): 95-106.

Dixit, A. K. (1989), “Entry and Exit Decisions under Uncertainty”, Journal of Political Economy, 97(3): 620-638.

Dixit, A. K. and Robert S. Pindyck (1994), "Investment under Uncertainty", Princeton, NJ, Princeton University Press.

Dutta, P. K., Saul Lach and Aldo Rustichini (1995), "Better Late than Early: Vertical Differentiation in the Adoption of a New Technology", Journal of Economics and Management Strategy, 4(4): 563-589.

Ericson, R. and Ariel Pakes (1995), "Markov-Perfect Industry Dynamics: A Framework for Empirical Work", Review of Economic Studies, 62(1): 53-82.

Fudenberg, D. and Jean Tirole (1985), "Preemption and Rent Equalization in the Adoption of New Technology", Review of Economic Studies, 52(3): 383-401. 
Fudenberg, D. and Jean Tirole (1986), “A Theory of Exit in Duopoly”, Econometrica, 54(4): 943-960.

Gilbert, R. J. (1989), "Mobility Barriers and the Value of Incumbency”, in Schmalensee, R. and Robert D. Willig eds, Handbook of Industrial Organization, Volume I, NorthHolland Amsterdam.

Ghemawat, P. (1991), “Commitment: The Dynamic of Strategy”, 1 st Edition, New York, NY, Free Press.

Ghemawat, P. and Barry Nalebuff (1985), "Exit", Rand Journal of Economics, 16(2): 184-194.

Hendricks, K. Andrew Weiss and Charles Wilson (1988), "The War of Attrition in Continuous Time with Complete Information", International Economic Review, 29(4): $663-680$.

Judd, K. L. (1985), “Credible Spatial Preemption”, Rand Journal of Economics, 16(2): $153-166$.

Lambrecht, B. (2001), “The Impact of Debt Financing on Entry and Exit in a Duopoly”, Review of Financial Studies, 14(3): 765-804.

Londregan, J. (1990), "Entry and Exit over the Industry Life Cycle", Rand Journal of Economics, 21(3): 446-458.

Murto, P. (2003), "Exit in Duopoly under Uncertainty", Rand Journal of Economics, forthcoming.

Shapiro, C. (1989), “The Theory of Business Strategy”, Rand Journal of Economics, 20(1): 125-137. 
Spencer, B. J. and James A. Brander (1992), "Pre-commitment and Flexibility. Applications to Oligopoly Theory", European Economic Review 36(8): 1601-1626. 


\section{APPENDIX}

Proof of Proposition 1: If both firms are present in the market at $t \in\left[t_{2}^{x}(2, \tau), \max \left\{t_{1}^{x}(2, \tau), t_{2}^{x}(1, \tau)\right\}\right)$, exit behavior has to consider the possibility of triggering a war of attrition. Playing "in" until $t_{1}^{x}(2, \tau)$ is dominant for firm 1 (by expression (1)), so we distinguish two cases. In the first place, let $t_{2}^{x}(1, \tau) \leq t_{1}^{x}(2, \tau)$. Then firm 1 is anticipated to stay at least until $t_{1}^{x}(2, \tau)$. Firm 2 is not willing to stay longer than $t_{2}^{x}(1, \tau) \leq t_{1}^{x}(2, \tau)$, so it solves $\max _{t^{\prime} \geq t} E_{2}\left(t^{\prime} \mid t, 2, \tau\right)$, given that it foresees a duopoly during its remaining lifetime. As a result, its best response is to exit immediately $\forall t \geq t_{2}^{x}(2, \tau)$ (by expression (1)). In turn, firm 1 solves $\max _{t^{\prime} \geq t} E_{1}\left(t^{\prime} \mid t, 1, \tau\right)$ and thus decides to exit only $\forall t \geq t_{1}^{x}(1, \tau)$. In the second place, let $t_{1}^{x}(2, \tau)<t_{2}^{x}(1, \tau)$ and consider first subgames starting at $t \in\left[t_{1}^{x}(2, \tau), t_{2}^{x}(1, \tau)\right)$ with both firms active. Taking into account that the game is effectively terminated at time $t_{2}^{x}(1, \tau)$, it is straightforward to check that Assumptions 1-3 and condition (a) of Theorem 4 in Hendricks, Weiss and Wilson (1988) hold. As a result, it follows that, if both firms are active at some $t \in\left[t_{1}^{x}(2, \tau), t_{2}^{x}(1, \tau)\right)$, then it is optimal for firm 2 to exit immediately $\forall t$. So now consider subgames indexed by $t \in\left[t_{2}^{x}(2, \tau), t_{1}^{x}(2, \tau)\right)$. Given the previous result and the fact that remaining until $t_{1}^{x}(2, \tau)$ is dominant for firm 1, it follows that firm 2's best-response is to exit immediately at $t$. In short, we have shown that firm 1 can credibly commit to outlast firm 2 , no matter how fierce firm 2's threat of playing in is. Hence, the unique subgame perfect equilibrium outcome of the exit subgame is characterized by firm 1 staying in the industry until $t_{1}^{x}(1, \tau)$, and firm 2 exiting at $t$. 
We examine now situations in which only one firm is active in the market, based on the previous analysis. Thus, it is clear that, if firm 1 is the only incumbent at $t \geq t_{2}^{x}(2, \tau)$, then firm 2's best response is to remain out of the market, and, consequently, firm 1's exit occurs at $t_{1}^{x}(1, \tau)$. If firm 2 is operating alone at $t \geq t_{2}^{x}(2, \tau)$, then there are two exclusive possibilities, depending on the solution to the entry problem faced by firm 1, $\max _{t^{\prime} \in\left[t, t_{1}^{x}(1, \tau)\right]} \int_{t^{\prime}}^{t_{1}^{x}(1, \tau)} D_{1}(s-\tau) e^{-r s} d s+S_{1} e^{-r t_{1}^{x}(1, \tau)}-K e^{-r t^{\prime}}$. The solution to this program is either $t$ or $t_{1}^{x}(1, \tau)$, due to the quasi-convexity of the objective function. ${ }^{30}$ Hence, if the solution is the former, then the equilibrium outcome is as follows: firm 1 enters at $t$ if the stream of discounted profits is non-negative and firm 2 exits immediately, with firm 1 staying in until $t_{1}^{x}(1, \tau)$. On the contrary, if the solution is the latter (or the stream of profits is negative), then the equilibrium outcome is as follows: firm 1 stays out of the market and firm 2 chooses to exit at $t_{2}^{x}(1, \tau)$. The cases in which neither firm is active are equally trivial: if the net present value of both firms is negative, then none of them enters; if it is negative only for one firm, then its competitor enters the market; finally, if both of them are not negative, then only firm 1 enters by the previous arguments

Proof of Lemma 1: Since $P V_{2}(t)$ is strictly quasi-convex on $(0, \infty)$ and attains an interior minimum at $\tau+D_{2}^{-1}(r K)<\tau$, where the inequality follows from $\frac{D_{2}(0)}{r}<\frac{D_{1}(0)}{r} \leq K, P V_{2}(t)$ must be strictly increasing on the set $\left[\tau, t_{2}^{x}(2, \tau)\right)$. Given that $P V_{2}\left(t_{2}^{x}(2, \tau)\right)<0$, we have the desired result.

\footnotetext{
${ }^{30}$ It could also be monotone increasing if $t^{\prime}$ is not smaller than the global minimum of the function.
} 
Proof of Lemma 2: $\int_{t}^{t_{1}^{x}(1, \tau)} D_{1}(s-\tau) e^{-r s} d s+S_{1} e^{-r r_{1}^{x}(1, \tau)}-K e^{-r t}$ is strictly quasi-convex on $(0, \infty)$ and attains an interior minimum at $\tau+D_{1}^{-1}(r K)<\tau$, so $P V_{1}(t)$ is monotone increasing on the set $\left[t_{2}^{x}(2, \tau), t_{1}^{x}(1, \tau)\right)$. Since $P V_{1}\left(t_{1}^{x}(1, \tau)\right)<0$, we have that $P V_{1}(t)<0 \forall t \in\left[t_{2}^{x}(2, \tau), t_{1}^{x}(1, \tau)\right) . \quad P V_{1}(t)$ is not differentiable at $t_{2}^{x}(2, \tau)$, albeit it is a continuous function, so to conclude the proof, it suffices to show that $P V_{1}(t)$ is monotone increasing on $\left[\tau, t_{2}^{x}(2, \tau)\right)$. This follows from the fact that the function is strictly quasi-convex on $(0, \infty)$ and attains an interior minimum at $\tau+D_{2}^{-1}(r K)<\tau$.

Proof of Lemma 3: $V_{1}^{f}(t)$ can be rewritten as follows:

$$
\begin{aligned}
V_{1}^{f}(t)= & \int_{t}^{\infty} f(\tau)\left[\int_{t}^{\tau} G_{2}(s) e^{-r s} d s+\int_{\tau}^{t_{2}^{x}(2, \tau)} D_{2}(s-\tau) e^{-r s} d s+\right. \\
& \left.\int_{t_{2}^{t}(2, \tau)}^{t_{1}^{x}(1, \tau)} D_{1}(s-\tau) e^{-r s} d s+S_{1} e^{-r t_{1}^{x}(1, \tau)}-K e^{-r t}\right] d \tau
\end{aligned}
$$

Differentiating $V_{1}^{f}(t)$ with respect to $t$, straightforward manipulations taking into account that $t_{i}^{x}(m, \tau)=\max \left(\tau, \tau+D_{m}^{-1}\left(r S_{i}\right)\right)$ yield:

$$
\begin{aligned}
\frac{d V_{1}^{f}(t)}{d t}= & -f(t)\left[\int_{t}^{t_{2}^{t}(2, t)} D_{2}(s-t) e^{-r s} d s+\int_{t_{2}^{x}(2, t)}^{t_{1}^{x}(1, t)} D_{1}(s-t) e^{-r s} d s+S_{1} e^{-r t_{1}^{x}(1, t)}-K e^{-r t}\right]- \\
& \int_{t}^{\infty}\left(G_{2}(t) e^{-r t}-r K e^{-r t}\right) f(\tau) d \tau=-\left(G_{2}(t)-r K\right) e^{-r t} \int_{t}^{\infty} f(\tau) d \tau- \\
& f(t) e^{-r t}\left(\int_{0}^{\max \left(0, D_{2}^{-1}\left(r S_{2}\right)\right)} D_{2}(s) e^{-r s} d s+\int_{\max \left(0, D_{2}^{-1}\left(r S_{2}\right)\right)}^{\max \left(0, D_{1}^{-1}\left(r S_{1}\right)\right)} D_{1}(s) e^{-r s} d s+S_{1} \min \left(1, e^{-r D_{1}^{-1}\left(r S_{1}\right)}\right)-K\right)
\end{aligned}
$$

For simplicity, let 


$$
A \equiv \int_{0}^{\max \left(0, D^{-1}\left(r S_{2}\right)\right)} D_{2}(s) e^{-r s} d s+\int_{\max \left(0, D_{2}^{-1}\left(r S_{2}\right)\right)}^{\max \left(0, D_{1}^{-1}\left(r S_{1}\right)\right)} D_{1}(s) e^{-r s} d s+S_{1} \min \left(1, e^{-r D_{1}^{-1}\left(r S_{1}\right)}\right)
$$

so that $\frac{d V_{1}^{f}(t)}{d t}=e^{-(r+\lambda) t}\left[(r+\lambda) K-\lambda A-G_{2}(t)\right] \quad$ because $\quad f(t)=\lambda e^{-\lambda t} \quad$ and $\int_{t}^{\infty} f(\tau) d \tau=e^{-\lambda t}$

For now, assume that $A<\frac{(r+\lambda) K-G_{2}(0)}{\lambda}$. (This is much easier to show once some additional notation has been introduced, and the proof of Lemma 4 below shows that this is indeed the case: see expression (3) in that proof.) Then, setting $\frac{d V_{1}^{f}(t)}{d t}=0$ and rearranging yields the candidate for global maximum:

$$
t_{1}^{f}=G_{2}^{-1}((r+\lambda) K-\lambda A)>0 .
$$

The inequality follows because of strict increasingness of $G_{2}(\cdot)$. Let us check that indeed we have a maximum, that is, $\frac{d^{2} V_{1}^{f}\left(t_{1}^{f}\right)}{d t^{2}}<0$. Since $\frac{d V_{1}^{f}(t)}{d t}=e^{-(r+\lambda) t}\left[(r+\lambda) K-\lambda A-G_{2}(t)\right]$, denoting derivatives by primes, we have that $\frac{d^{2} V_{1}^{f}\left(t_{1}^{f}\right)}{d t^{2}}=-e^{-(r+\lambda) t_{1}^{f}}\left\{(r+\lambda)\left[(r+\lambda) K-\lambda A-G_{2}\left(t_{1}^{f}\right)\right]+G_{2}^{\prime}\left(t_{1}^{f}\right)\right\}<0$

because $G_{2}\left(t_{1}^{f}\right)=(r+\lambda) K-\lambda A$ by definition of $t_{1}^{f}$, and $G_{2}^{\prime}(\cdot)>0$. Given that $\lim _{t \rightarrow \infty} V_{1}^{f}(t)=0$, the (continuity and) differentiability of $V_{1}^{f}(\cdot)$ imply that we must have that $V_{1}^{f}(t)>0 \forall t \geq t_{1}^{f}$.

Similarly, it can be shown that 


$$
V_{2}^{f}(t)=\int_{t}^{\infty} f(\tau)\left[\int_{t}^{\tau} G_{2}(s) e^{-r s} d s+\int_{\tau^{R}}^{t_{2}^{x}(2, \tau)} D_{2}(s-\tau) e^{-r s} d s+S_{2} e^{-r t_{2}^{x}(2, \tau)}-K e^{-r t}\right] d \tau
$$

is strictly quasi-concave with its maximum attained at $t_{2}^{f}=G_{2}^{-1}((r+\lambda) K-\lambda B)>0$, where $B \equiv \int_{0}^{\max \left(0, D_{2}^{-1}\left(r S_{2}\right)\right)} D_{2}(s) e^{-r s} d s+S_{2} \min \left(1, e^{-r D_{2}^{-1}\left(r S_{2}\right)}\right)$. (Again, we postpone the proof that $B<\frac{(r+\lambda) K-G_{2}(0)}{\lambda}$ and refer to expression (4) in the proof of Lemma 4.) Finally, the last statement of the lemma follows from straightforward manipulations.

Proof of Lemma 4: By Lemma 3, $V_{i}^{f}(t)$ is strictly decreasing on $\left(t_{j}^{f}, \infty\right)$, so by the continuity of $V_{i}^{l}(t)$ it suffices to show that this function is single-peaked on $t \in\left[0, t_{j}^{f}\right]$. We focus on this subset of dates for the reminder of the proof. Consider first the case in which $i=1$. Differentiating $V_{1}^{l}(t)$ with respect to $t$, performing simple operations and

$$
\begin{aligned}
& \text { letting } C \equiv \int_{0}^{\max \left(0, D_{1}^{-1}\left(r S_{1}\right)\right)} D_{1}(s) e^{-r s} d s+S_{1} \min \left(1, e^{-r D_{1}^{-1}\left(r S_{1}\right)}\right) \text { yields: } \\
& \qquad \begin{aligned}
\frac{d V_{1}^{l}(t)}{d t}= & -f(t)\left[\int_{t}^{t_{1}^{x}(1, t)} D_{1}(s-t) e^{-r s} d s+S_{1} e^{-r t_{1}^{x}(1, t)}-K e^{-r t}\right]+\int_{t}^{\infty} r K e^{-r t} f(\tau) d \tau- \\
& \int_{t}^{t_{2}^{f}} G_{1}(t) e^{-r t} f(\tau) d \tau-\int_{t_{2}^{f}}^{\infty} G_{1}(t) e^{-r t} f(\tau) d \tau=-\left(G_{1}(t)-r K\right) e^{-r t} \int_{t}^{\infty} f(\tau) d \tau- \\
& f(t) e^{-r t}\left(\int_{0}^{\max \left(0, D_{1}^{-1}\left(r S_{1}\right)\right)} D_{1}(s) e^{-r s} d s+S_{1} \min \left(1, e^{-r D_{1}^{-1}\left(r S_{1}\right)}\right)-K\right)= \\
& e^{-(r+\lambda) t}\left[(r+\lambda) K-\lambda C-G_{1}(t)\right]
\end{aligned}
\end{aligned}
$$


For the moment, suppose that $C<\frac{(r+\lambda) K-G_{1}(0)}{\lambda}$ (see expression (3) below for a proof that this always holds). Then, setting $\frac{d V_{1}^{l}(t)}{d t}=0$ and rearranging yields the candidate for global maximum:

$$
t_{1}^{l}=G_{1}^{-1}((r+\lambda) K-\lambda C)>0 .
$$

It is straightforward to prove that $\frac{d^{2} V_{1}^{l}\left(t_{1}^{l}\right)}{d t^{2}}<0$, as well as that $V_{1}^{l}(t)>0 \forall t \geq t_{1}^{l}$. If $t_{1}^{l}$ were greater than $t_{2}^{f}$, then it is easy to show that $V_{1}^{l}(t)$ is monotone increasing on $\left[0, t_{2}^{f}\right)$, so $t_{1}^{f}$ would be the global maximum by continuity.

The proof for $V_{2}^{l}(t)$ is identical, replacing $C$ with $D \equiv \int_{0}^{\max \left(0, D_{1}^{-1}\left(r S_{2}\right)\right)} D_{1}(s) e^{-r s} d s+S_{2} \min \left(1, e^{-r D_{1}^{-1}\left(r S_{2}\right)}\right)$. In this case, $t_{2}^{l}=G_{1}^{-1}((r+\lambda) K-\lambda D)>0$ when $D<\frac{(r+\lambda) K-G_{1}(0)}{\lambda}$.

We now show that it is always the case that $D<\frac{(r+\lambda) K-G_{1}(0)}{\lambda}$. First, note that $K \geq \frac{D_{1}(0)}{r}$ implies that $\frac{(r+\lambda) K-D_{1}(0)}{\lambda} \geq K$. Given that the function $R\left(S_{2}\right)=\int_{0}^{\max \left(0, D_{1}^{-1}\left(r S_{2}\right)\right)} D_{1}(s) e^{-r s} d s+S_{2} \min \left(1, e^{-r D_{1}^{-1}\left(r S_{2}\right)}\right)$ can be easily shown to be monotone increasing and $R(K)=K \quad$ as $D_{1}^{-1}(r K) \leq 0$ by Assumption 3), it follows that $R\left(S_{2}\right)<K \forall S_{2}$, i.e., $D<K$, so we have that $\frac{(r+\lambda) K-D_{1}(0)}{\lambda}>D$. The fact that $D_{1}(0) \geq G_{1}(0)$ yields the desired result. 
It can also be proven that $D>C \geq A$, from where it follows that $t_{2}^{l}<t_{1}^{l}<t_{1}^{f}$ :

$$
\begin{aligned}
& D=e^{r \tau}\left(\int_{\tau}^{t_{2}^{x}(1, \tau)} D_{1}(s-\tau) e^{-r s} d s+S_{2} e^{-r t_{2}^{x}(1, \tau)}\right) \geq e^{r \tau}\left(\int_{\tau}^{t_{1}^{x}(1, \tau)} D_{1}(s-\tau) e^{-r s} d s+S_{2} e^{-r t_{2}^{x}(1, \tau)}\right)> \\
& e^{r \tau}\left(\int_{\tau}^{t_{1}^{x}(1, \tau)} D_{1}(s-\tau) e^{-r s} d s+S_{1} e^{-r t_{2}^{x}(1, \tau)}\right)=C \geq \\
& e^{r \tau}\left(\int_{\tau}^{t_{2}^{x}(2, \tau)} D_{2}(s-\tau) e^{-r s} d s+\int_{t_{2}^{x}(2, \tau)}^{t_{1}^{x}(1, \tau)} D_{1}(s-\tau) e^{-r s} d s+S_{1} e^{-r t_{1}^{x}(1, \tau)}\right)=A,
\end{aligned}
$$

where the first inequality follows from a revealed preference argument and the last one makes use of the fact that $D_{1}(s-\tau)>D_{2}(s-\tau)$. Note that we have also proven that

$$
\frac{(r+\lambda) K-G_{2}(0)}{\lambda}>\frac{(r+\lambda) K-G_{1}(0)}{\lambda}>D>C \geq A
$$

Another revealed preference argument and $D_{1}(s-\tau)>D_{2}(s-\tau)$ imply that

$$
\begin{aligned}
& D=e^{r \tau}\left(\int_{\tau}^{t_{2}^{x}(1, \tau)} D_{1}(s-\tau) e^{-r s} d s+S_{2} e^{-r t_{2}^{x}(1, \tau)}\right) \geq e^{r \tau}\left(\int_{\tau}^{t_{2}^{x}(2, \tau)} D_{1}(s-\tau) e^{-r s} d s+S_{2} e^{-r t_{2}^{x}(2, \tau)}\right) \geq \\
& e^{r \tau}\left(\int_{\tau}^{t_{2}^{x}(2, \tau)} D_{2}(s-\tau) e^{-r s} d s+S_{2} e^{-r t_{2}^{x}(2, \tau)}\right)=B,
\end{aligned}
$$

from where it clearly follows that $t_{2}^{l}<t_{2}^{f}$ because $G_{1}(\cdot)$ is strictly increasing and $G_{1}(t)>G_{2}(t)$. Note this also proves the following:

$$
\frac{(r+\lambda) K-G_{2}(0)}{\lambda}>\frac{(r+\lambda) K-G_{1}(0)}{\lambda}>D \geq B
$$

This completes the proof.

Proof of Proposition 3: Of course, due to Proposition 2 and the temporary assumption that no incumbent is willing to exit a growing industry once it has entered, it suffices to show that the entry game has a unique equilibrium. For each of the cases, we first exhibit 
a pair of (subgame perfect) equilibrium strategies and then prove the uniqueness of such strategies, taking into account that each firm would play its best-response if its rival had already entered. Also, note that all the strategies exhibited below are contingent on the market still growing.

In the first place, suppose that $t_{2}^{l}<t_{2}^{f}<t_{1}^{f}$ (this situation is represented in Figure 3) and consider the following strategy profile: if no firm has entered at date $t \geq 0$, then firm 2 tries to enter immediately if only if $t \geq t_{2}^{l}$, while firm 1 tries to enter immediately if only if $t \geq t_{1}^{f}$.

Let us check that this profile of strategies indeed forms a subgame perfect equilibrium. For subgames starting at $t \geq t_{i}^{f}$, decreasingness of both $L_{i}(\cdot)$ and $F_{i}(\cdot)$ implies that firm $i(i=1,2)$ has a dominant strategy: to enter immediately. For $t \in\left[0, t_{1}^{f}\right)$, the fact that $F_{1}\left(t_{1}^{f}\right)$ is the maximum attainable payoff and $L_{1}(t)<F_{1}\left(t_{1}^{f}\right)$ (since $L_{1}(\cdot)$ is monotone increasing on $\left[0, t_{1}^{f}\right]$ by Lemma 4 because $\left.\hat{t}_{1}=t_{1}^{f}\right)$ implies that no entry is a dominant strategy for firm 1 on that set of subgame start dates. For $t \in\left[t_{2}^{l}, t_{2}^{f}\right)$, it is dominant for firm 2 to enter right away since $L_{2}(\cdot)$ is decreasing on that set and $(1-p) L_{2}(t)+p F_{2}\left(t_{2}^{f}\right)>F_{2}\left(t_{2}^{f}\right)$ for $t \in\left[t_{2}^{l}, t_{2}^{f}\right)$ (by Assumption 6, if both attempted to enter at the same time, firm 2 would succeed only with probability $1-p$ ). If $t_{2}^{*}$ is finite, then, for $t \in\left[0, t_{2}^{*}\right)$, it is dominant for firm 2 to wait, since firm 2 prefers to follow. If it is infinite or $t \in\left(t_{2}^{*}, t_{2}^{l}\right)$ (so that $L_{2}(t)>F_{2}\left(t_{2}^{f}\right)$ on that set), then the increasingness of $L_{2}(\cdot)$ implies that firm 2 would be better off by waiting if firm 1 entered at some later date. But if firm 1 entered at $t$, then firm 2 would also rather enter immediately, since 
$(1-p) L_{2}(t)+p F_{2}\left(t_{2}^{f}\right)>F_{2}\left(t_{2}^{f}\right)$. Therefore, we have just shown that it is dominant for firm 2 to wait if $t \in\left[0, t_{2}^{l}\right)$, which completes the proof that the exhibited strategies form a subgame perfect equilibrium. Regarding the uniqueness of the equilibrium, it follows trivially in this case because the presented strategies are dominant.

In the second place, suppose that $t_{2}^{l}<t_{1}^{l}<t_{2}^{f}<t_{1}^{f}$ (this situation is represented in Figure 2). If $L_{1}\left(t_{1}^{l}\right) \leq F_{1}\left(t_{1}^{f}\right)$, then the situation is exactly as in the previous case, so let $L_{1}\left(t_{1}^{l}\right)>F_{1}\left(t_{1}^{f}\right)$. Then we claim that we must have that $t_{2}^{*}<t_{1}^{*}$. Since $L_{2}(t)>L_{1}(t)$ and $\frac{d\left(L_{2}(t)-L_{1}(t)\right)}{d t}<0 \forall t \in\left[0, t_{2}^{f}\right],{ }^{31}$ the following must hold:

$L_{2}(t)-L_{1}(t)>L_{2}\left(t_{2}^{f}\right)-L_{1}\left(t_{2}^{f}\right)>V_{2}^{f}\left(t_{2}^{f}\right)-V_{1}^{f}\left(t_{2}^{f}\right)>V_{2}^{f}\left(t_{2}^{f}\right)-V_{1}^{f}\left(t_{1}^{f}\right)=F_{2}\left(t_{2}^{f}\right)-F_{1}\left(t_{1}^{f}\right)$.

Thus, given that $F_{2}\left(t_{2}^{f}\right)-F_{1}\left(t_{1}^{f}\right)<L_{2}(t)-L_{1}(t) \forall t \in\left[0, t_{2}^{f}\right]$, we would reach the following contradiction if $t_{1}^{*} \leq t_{2}^{*}$ (recall that we have ruled out $t_{i}^{*}=0 \forall i$ ):

$$
L_{2}\left(t_{1}^{*}\right)-L_{1}\left(t_{1}^{*}\right) \leq L_{2}\left(t_{2}^{*}\right)-L_{1}\left(t_{1}^{*}\right) \leq F_{2}\left(t_{2}^{f}\right)-F_{1}\left(t_{1}^{f}\right)<L_{2}\left(t_{1}^{*}\right)-L_{1}\left(t_{1}^{*}\right)
$$

where the first inequality follows because $t_{2}^{*}<t_{2}^{l}$ (so $L_{2}(\cdot)$ is monotone increasing on that range). This shows that indeed $t_{2}^{*}<t_{1}^{*}$.

For simplicity, let $t_{1}^{*} \leq t_{2}^{l}$ (the analysis is similar, or even simpler, if $t_{2}^{l}<t_{1}^{*}$ ) and consider the following strategy profile: if no firm has entered at date $t \geq 0$, then firm 2 tries to enter immediately $\forall t \geq t_{1}^{*}$ and waits $\forall t \in\left[0, t_{1}^{*}\right)$, while firm 1 tries to enter immediately $\forall t \in\left(t_{1}^{*}, t_{1}^{c}\right) \cup\left[t_{1}^{f}, \infty\right) \quad$ and $\quad$ waits $\quad \forall t \in\left[0, t_{1}^{*}\right] \cup\left[t_{1}^{c}, t_{1}^{f}\right), \quad$ where $t_{1}^{c}=\sup \left\{t \in\left[0, t_{2}^{f}\right): L_{1}(t) \geq F_{1}\left(t_{1}^{f}\right)\right\}$. We claim that this pair of strategies constitutes an

$31 \frac{d\left(L_{2}(t)-L_{1}(t)\right)}{d t}=e^{-(r+\lambda) t}\left((r+\lambda) K-\lambda D-G_{1}(t)-(r+\lambda) K+\lambda C+G_{1}(t)\right)=\lambda e^{-(r+\lambda) t}(C-D)<0, \quad$ since $C<D$ as shown in the proof of Lemma 4 . 
equilibrium, so let us fix firm 2's strategy and consider the incentives of firm 1 to deviate. It is clear that immediate entry is dominant for firm 1 if $t \geq t_{1}^{f}$, while waiting is dominant for $t \in\left[0, t_{1}^{*}\right] \cup\left[t_{1}^{c}, t_{1}^{f}\right)$. For subgames starting at $t \in\left(t_{1}^{*}, t_{1}^{c}\right)$, firm 2's strategy prescribes immediate entry, so firm 1's best-response is to enter right away since $p L_{1}(t)+(1-p) F_{1}\left(t_{1}^{f}\right)>F_{1}\left(t_{1}^{f}\right)$. Now let us check firm 2's incentives to deviate. Immediate entry is clearly dominant for $t \geq t_{2}^{l}$, and waiting is also dominant for $t \in\left[0, t_{1}^{*}\right)$, since $t_{1}^{*} \leq t_{2}^{l}$ (the argument is identical to the one used in the proof of the first type of equilibrium). For $t^{\prime} \in\left(t_{1}^{*}, t_{2}^{l}\right)$, firm 1's strategy entails immediate entry. Therefore, firm 2's best-response on $t \in\left[t_{1}^{*}, t_{2}^{l}\right)$ is to enter right away, given that $L_{2}(t)>(1-p) L_{2}\left(t^{\prime}\right)+p F_{2}\left(t_{2}^{f}\right)>F_{2}\left(t_{2}^{f}\right) \quad$ (the first inequality is only used for $t$ sufficiently close to $t^{\prime}$, so it follows that it holds from the continuity of $\left.L_{2}(\cdot)\right)$.

Proving uniqueness is simple in this case too, so let us consider any perfect equilibrium. Given the previous analysis, we can restrict our attention to subgames starting at dates $t \in\left[t_{1}^{*}, t_{2}^{l}\right)$, since it is clear that firm 1's best-response to firm 2's dominant strategy on $t \in\left[t_{2}^{l}, t_{1}^{c}\right)$ is to enter immediately by Assumption 6. So let us consider subgames starting at $t \in\left(t_{1}^{*}, t_{2}^{l}\right)$. It is clear that Assumption 6 implies that we cannot have only one firm entering at $t$. Also, entry in equilibrium cannot occur at some later date $t^{\prime} \in\left(t, t_{2}^{l}\right)$, because any firm would do better by preempting its rival by entering at $t^{\prime}-\varepsilon$ (where $\varepsilon>0$ is infinitesimally small), and thus getting $L_{i}\left(t^{\prime}-\varepsilon\right)$, which is greater than $F_{i}\left(t_{i}^{f}\right)$ and the payoff to simultaneous entry at $t$ (by continuity of $L_{i}(\cdot)$ ). Hence, it is in both firm's interest to try to enter for all $t \in\left(t_{1}^{*}, t_{2}^{l}\right)$. For subgames starting at $t=t_{1}^{*}$, firm 1 prefers 
not to enter at $t$. Anticipating the equilibrium outcome on subsequent subgames if it does not enter at $t$, firm 2 clearly prefers to preempt its rival and enter immediately.

In the last place, let $t_{2}^{l}<t_{1}^{l}<t_{1}^{f} \leq t_{2}^{f}$ (this situation is represented in Figure 4). This case is trivial if $L_{2}\left(t_{2}^{l}\right) \leq F_{2}\left(t_{2}^{f}\right)$, so let us suppose that $L_{2}\left(t_{2}^{l}\right)>F_{2}\left(t_{2}^{f}\right)$. If $t_{1}^{*}<t_{2}^{*}$, the situation is analogous to the one in which $t_{2}^{l}<t_{1}^{l}<t_{2}^{f}<t_{1}^{f}$, just interchanging the identities of the firms. In turn, if $t_{2}^{*} \leq t_{1}^{*}$, given that the analysis follows the same steps we performed as in the second case, we simply exhibit the unique pair of equilibrium strategies (for the more complicated case in which $t_{1}^{*} \leq t_{2}^{l}$ ): if no firm has entered at date $t \geq 0$, then firm 1 tries to enter immediately $\forall t>t_{1}^{*}$ and waits $\forall t \in\left[0, t_{1}^{*}\right]$, while firm 2 tries to enter immediately $\forall t \in\left[t_{1}^{*}, t_{2}^{c}\right) \cup\left[t_{2}^{f}, \infty\right)$ and waits $\forall t \in\left[0, t_{1}^{*}\right) \cup\left[t_{2}^{c}, t_{2}^{f}\right)$, where $t_{2}^{c}=\sup \left\{t \in\left[0, t_{1}^{f}\right): L_{2}(t) \geq F_{2}\left(t_{2}^{f}\right)\right\}$

Proof of Proposition 4: If (2) is not met, then $t_{2}^{f}<t_{1}^{f}$, so, as shown in the proof of Proposition 3, the equilibrium outcome is characterized by firm 2 entering at $t_{2}^{l}$ (if $\left.\hat{t}_{1}=t_{1}^{f}\right)$ or at $\min \left(t_{2}^{l}, t_{1}^{*}\right)$ (if $\hat{t}_{1}=t_{1}^{l}$ ) and firm 1 entering at $t_{1}^{f}$. This shows that firm 2 enters first. In addition, note that firm 1 always gets $F_{1}\left(t_{1}^{f}\right)$. If firm 2 enters at $t_{2}^{l}$, then $F_{1}\left(t_{1}^{f}\right)<L_{2}\left(t_{1}^{f}\right)<L_{2}\left(t_{2}^{l}\right)$, whereas, if firm 2 enters at $t_{1}^{*}$, then $F_{1}\left(t_{1}^{f}\right) \leq L_{1}\left(t_{1}^{*}\right)<L_{2}\left(t_{1}^{*}\right)$ This ends the proof.

Proof of Proposition 5: The first claim follows from a direct application of Proposition 4. Now let $G_{m}(t)=\pi(m) G(t)$. We proceed to show that $t_{2}^{f} \leq \hat{t}_{1}=t_{1}^{f}$ if $\frac{\pi(1)-\pi(2)}{\pi(1)} \geq \frac{Z}{1+Z}$. Suppose to the contrary that $\hat{t}_{1}=t_{1}^{l}<t_{2}^{f}\left(\hat{t}_{1}=t_{1}^{f}<t_{2}^{f}\right.$ cannot hold 
because (2) is not met), so that $\frac{(r+\lambda) K-\lambda C}{\pi(1)}<\frac{(r+\lambda) K-\lambda B}{\pi(2)}$ holds because $G_{1}\left[G_{2}^{-1}((r+\lambda) K-\lambda B)\right]=\frac{\pi(1)((r+\lambda) K-\lambda B)}{\pi(2)}$. Since $C \rightarrow \int_{0}^{\infty} D_{1}(s) e^{-r s} d s$ and $B \rightarrow K$, $\frac{(r+\lambda) K-\lambda Y}{\pi(1)} \leq \frac{r K}{\pi(2)} \quad$ implies $\quad$ that $\quad\left(\frac{(r+\lambda) \pi(2)-r \pi(1)}{\pi(2)}\right) K \leq \lambda Y, \quad$ where $Y \equiv \int_{0}^{\infty} D_{1}(s) e^{-r s} d s . \quad$ Given that $\quad K \geq \frac{D_{1}(0)}{r}, \quad \frac{(r+\lambda) \pi(2)-r \pi(1)}{\pi(2)}<\frac{\lambda Y}{D_{1}(0) / r}, \quad$ so $r+\lambda<r \frac{\pi(1)}{\pi(2)}+\frac{\lambda Y}{D_{1}(0) / r} . \quad$ Simple manipulations $\quad$ yield $\frac{\pi(1)-\pi(2)}{\pi(2)}>\lambda\left(\frac{D_{1}(0) / r-Y}{D_{1}(0) / r}\right)=Z$, which contradicts the fact that $\frac{\pi(1)-\pi(2)}{\pi(1)} \geq \frac{Z}{1+Z}$

This is the desired result, which, together with the equilibrium outcome of the first case analyzed in the proof of Proposition 3, completes the proof.

Proof of Proposition 6: It is easy to see that $t_{1}^{f}, t_{2}^{f} \rightarrow \infty$ as $G_{2}(\cdot) \rightarrow 0$ pointwise. The fact that no firm would enter as a duopolist in a declining market implies that $L_{1}(t)>L_{2}(t)$ on $t \in[0, \infty)$. Clearly, the outcome of the game is characterized by firm 2 entering at $\min \left(t_{2}^{l}, t_{1}^{*}\right)$, where $t_{1}^{*} \geq 0$ is such that $L_{1}\left(t_{1}^{*}\right)=0$. Also, note that $L_{2}\left(t_{2}^{l}\right) \geq L_{2}\left(t_{1}^{*}\right)>L_{1}\left(t_{1}^{*}\right) \geq 0$

Proof of Proposition 7: Suppose that $S_{1}=S_{2}=S$, and consider the left-hand-side of (2) to be a function of $S, M(S)$ say, so that it can be rewritten as $M(S)=\int_{\max \left(0, D_{2}^{-1}(r S)\right)}^{\max \left(0, D_{1}^{-1}(r S)\right)}\left(D_{1}(t)-r S\right) e^{-r t} d t . \quad M(S)$ is clearly continuous, with $M(S)=0$ for 
$S \in\left[\frac{D_{1}(0)}{r}, K\right)$, and $M^{\prime}(S)<0$ on $S \in\left[\frac{D_{2}(0)}{r}, \frac{D_{1}(0)}{r}\right]$. I now show that $M(S)$ is strictly increasing on $S \in\left[0, \frac{D_{2}(0)}{r}\right)$. Since $M(0)=0$, the continuity of the function will imply that $M(S)>0 \quad \forall S \in\left(0, \frac{D_{1}(0)}{r}\right)$, and $M(S)=0 \quad \forall S \in\left[\frac{D_{1}(0)}{r}, K\right)$. So let $S \in\left[0, \frac{D_{2}(0)}{r}\right)$, so that $M(S)=\int_{D_{2}^{-1}(r S)}^{D_{1}^{-1}(r S)}\left(D_{1}(t)-r S\right) e^{-r t} d t$. Differentiating and performing simple algebraic manipulations yields:

$$
M^{\prime}(S)=\frac{e^{-r D_{2}^{-1}(r S)}}{D_{2}^{\prime}\left(D_{2}^{-1}(r S)\right)}\left[r\left(r S-D_{1}\left(D_{2}^{-1}(r S)\right)\right)-\left(1-e^{-r\left(D_{1}^{-1}(r S)-D_{2}^{-1}(r S)\right)}\right) D_{2}^{\prime}\left(D_{2}^{-1}(r S)\right)\right]
$$

If $M^{\prime}\left(S^{*}\right)=0$ for some $S^{*}$, then the following would hold:

$$
\begin{aligned}
M^{\prime \prime}\left(S^{*}\right)= & \frac{e^{-r D_{2}^{-1}(r S)}}{D_{2}^{\prime}\left(D_{2}^{-1}(r S)\right)}\left[D_{2}^{\prime \prime}\left(D_{2}^{-1}(r S)\right)\left(e^{-r\left(D_{1}^{-1}(r S)-D_{2}^{-1}(r S)\right)}-1\right)+r^{2}\left(1-\frac{D_{1}^{\prime}\left(D_{1}^{-1}(r S)\right)}{D_{2}^{\prime}\left(D_{2}^{-1}(r S)\right)}\right)-\right. \\
& \left.r^{2} D_{2}^{\prime}\left(D_{2}^{-1}(r S)\right) e^{-r\left(D_{1}^{-1}(r S)-D_{2}^{-1}(r S)\right)}\left(\frac{1}{D_{1}^{\prime}\left(D_{1}^{-1}(r S)\right)}-\frac{1}{D_{2}^{\prime}\left(D_{2}^{-1}(r S)\right)}\right)\right]>0,
\end{aligned}
$$

since $D_{1}^{\prime}\left(D_{1}^{-1}(r S)\right)=D_{2}^{\prime}\left(D_{2}^{-1}(r S)\right)$ and $D_{2}^{\prime \prime}\left(D_{2}^{-1}(r S)\right)>0$. So $M(S)$ is strictly quasiconvex on $S \in\left[0, \frac{D_{2}(0)}{r}\right)$. Since $S^{*}=0$, it follows that $M(S)$ is monotone increasing on $S \in\left[0, \frac{D_{2}(0)}{r}\right)$. Given all the analysis above, it is clear that, as $S_{1} \uparrow S_{2}$, (2) does not hold if and only if $S_{2} \in\left[\frac{D_{1}(0)}{r}, K\right)$. So the "only if" part of the statement follows directly from Proposition 4. If $S_{2}<\frac{D_{1}(0)}{r}$, then $t_{2}^{l}<t_{1}^{l}<t_{1}^{f}<t_{2}^{f}$. Further, the following holds: 


$$
F_{1}\left(t_{1}^{f}\right)-F_{2}\left(t_{2}^{f}\right)<F_{1}\left(t_{1}^{f}\right)-F_{2}\left(t_{1}^{f}\right)<L_{1}(t)-L_{2}(t)
$$

Only the last inequality requires proof, so suppose this were not the case. Then:

$$
\begin{aligned}
& F_{1}\left(t_{1}^{f}\right)-F_{2}\left(t_{1}^{f}\right)=\int_{t_{1}^{f}}^{\infty} f(\tau)\left(\int_{t_{2}^{x}(2, \tau)}^{t_{1}^{x}(1, \tau)} D_{1}(s-\tau) e^{-r s} d s+S_{1} e^{-r t_{1}^{x}(1, \tau)}-S_{2} e^{-r t_{2}^{t}(2, \tau)}\right) d \tau \geq \\
& L_{1}(t)-L_{2}(t)=\int_{t_{1}^{f}}^{t_{2}^{f}} f(\tau)\left(\int_{t_{1}^{f}}^{\tau}\left(G_{1}(s)-G_{2}(s)\right) e^{-r s} d s+\int_{\tau}^{t_{2}^{x}(2, \tau)}\left(D_{1}(s-\tau)-D_{2}(s-\tau)\right) e^{-r s} d s+\right. \\
& \left.\int_{t_{1}^{x}(1, \tau)}^{t_{2}^{x}(2, \tau)} D_{1}(s-\tau) e^{-r s} d s+S_{1} e^{-r t_{1}^{x}(1, \tau)}-S_{2} e^{-r t_{2}^{x}(2, \tau)}\right) d \tau+ \\
& \int_{t_{2}^{f}}^{\infty} f(\tau)\left(\int_{t_{1}^{f}}^{t_{2}^{f}}\left(G_{1}(s)-G_{2}(s)\right) e^{-r s s} d s+\int_{t_{2}^{t}(2, \tau)}^{t_{1}^{x}(1, \tau)} D_{1}(s-\tau) e^{-r s} d s+S_{1} e^{-r t_{1}^{x}(1, \tau)}-S_{2} e^{-r t_{2}^{x}(2, \tau)}\right) d \tau .
\end{aligned}
$$

Straightforward manipulations would deliver the following contradiction: ${ }^{32}$

$$
\begin{aligned}
0 \geq & \int_{t_{2}^{\prime}}^{\infty} f(\tau)\left(\int_{t_{1}^{\prime}}^{t_{2}^{\prime}}\left(G_{1}(s)-G_{2}(s)\right) e^{-r s} d s\right) d \tau+ \\
& \int_{t_{1}^{\prime}}^{t_{2}^{\prime}} f(\tau)\left(\int_{t_{1}^{\prime}}^{\tau}\left(G_{1}(s)-G_{2}(s)\right) e^{-r s} d s+\int_{\tau}^{t_{2}^{\tau}(2, \tau)}\left(D_{1}(s-\tau)-D_{2}(s-\tau)\right) e^{-r s} d s\right) d \tau>0,
\end{aligned}
$$

since $G_{1}(\cdot)>G_{2}(\cdot)$ and $D_{1}(\cdot)>D_{2}(\cdot)$.

As a result, $\quad F_{1}\left(t_{1}^{f}\right)-F_{2}\left(t_{2}^{f}\right)<L_{1}(t)-L_{2}(t), \quad$ so $\quad t_{1}^{*}<t_{2}^{*} \quad$ because, otherwise, $L_{1}\left(t_{2}^{*}\right)-L_{2}\left(t_{2}^{*}\right) \leq L_{1}\left(t_{1}^{*}\right)-L_{2}\left(t_{2}^{*}\right) \leq F_{1}\left(t_{1}^{f}\right)-F_{2}\left(t_{2}^{f}\right)<L_{1}\left(t_{2}^{*}\right)-L_{2}\left(t_{2}^{*}\right)$, which cannot be. Therefore, it can be easily shown that the unique subgame perfect equilibrium outcome is characterized by firm 1 entering at $t_{2}^{*}<t_{2}^{l}$ (if the market is still in growth at such date) and firm 2 following at $t_{2}^{f}$. It only remains to show that firm 1's equilibrium payoff is greater than that of firm 2, which follows from the fact that $F_{2}\left(t_{2}^{f}\right) \leq L_{2}\left(t_{2}^{*}\right)<L_{1}\left(t_{2}^{*}\right)$.

\footnotetext{
${ }^{32}$ Actually, because $S_{1}$ is slightly smaller than $S_{2}, L_{1}(t)-L_{2}(t)$ should include another term, $\varepsilon$, where $\varepsilon<0$ is infinitesimally large. This may convert the weak inequality into a strict one, and thereby it would not change the results.
} 
Proof of Proposition 8: Given the functional forms we have assumed, it is straightforward to show that (2) does not hold if and only if

$$
\begin{aligned}
& \frac{\pi(1)}{\alpha+r} \min \left(1,\left(\frac{r S_{1}}{\pi(1)}\right)^{\frac{\alpha+r}{\alpha}}\right)-S_{1} \min \left(1,\left(\frac{r S_{1}}{\pi(1)}\right)^{\frac{r}{\alpha}}\right)> \\
& \frac{\pi(1)}{\alpha+r} \min \left(1,\left(\frac{r S_{2}}{\pi(2)}\right)^{\frac{\alpha+r}{\alpha}}\right)-S_{2} \min \left(1,\left(\frac{r S_{2}}{\pi(2)}\right)^{\frac{r}{\alpha}}\right)
\end{aligned}
$$

Let us consider the left- and right-hand sides to be functions of $S_{1}$ and $S_{2}$, respectively. $M_{1}\left(S_{1}\right)=\frac{\pi(1)}{\alpha+r} \min \left(1,\left(\frac{r S_{1}}{\pi(1)}\right)^{\frac{\alpha+r}{\alpha}}\right)-S_{1} \min \left(1,\left(\frac{r S_{1}}{\pi(1)}\right)^{\frac{r}{\alpha}}\right)$ is a decreasing function on the set $(0, K)$, with $M_{1}(0)=0$. It is strictly concave on $\left(0, \frac{\pi(1)}{r}\right)$ and linear on $\left(\frac{\pi(1)}{r}, K\right)$. Furthermore, it is continuous and differentiable. To see that $M_{1}(\cdot)$ is differentiable at $\frac{\pi(1)}{r}$, note that its left- and right-derivatives at $\frac{\pi(1)}{r}$ are both equal to -1 .

When $\frac{\pi(1)-\pi(2)}{\pi(1)} \geq \frac{\alpha}{\alpha+r}, M_{2}\left(S_{2}\right)=\frac{\pi(1)}{\alpha+r} \min \left(1,\left(\frac{r S_{2}}{\pi(2)}\right)^{\frac{\alpha+r}{\alpha}}\right)-S_{2} \min \left(1,\left(\frac{r S_{2}}{\pi(2)}\right)^{\frac{r}{\alpha}}\right)$ is a continuous function that is increasing and strictly concave on the set $\left(0, \frac{\pi(2)}{r}\right)$ and linearly decreasing on $\left(\frac{\pi(2)}{r}, K\right)$, with slope equal to -1 . Also, $M_{2}\left(\frac{\pi(2)}{r}\right)=\frac{r \pi(1)-(\alpha+r) \pi(2)}{r(\alpha+r)} \geq 0$ and $M_{2}(0)=0$. 
Graphically, we have the situation depicted in Figure 6, from where it follows that, for $S_{2} \geq \frac{\pi(1)}{r}$, there exists no $S_{1}$ such that (2) holds. For $S_{2}<\frac{\pi(1)}{\alpha+r}$, there exists no $S_{1}$ such that (2) does not hold. Finally, for $S_{2} \in\left[\frac{\pi(1)}{\alpha+r}, \frac{\pi(1)}{r}\right)$, there exists a $S_{1}^{\prime}$ such that (2) does not hold for $S_{1} \in\left[S_{1}^{\prime}, S_{2}\right.$ ). Note also that a reduction in $S_{2}$ would decrease $S_{1}^{\prime}$ by a larger amount than the decrease in $S_{2}$, from where the concave property of $Q(\cdot)$ follows

Proof of Proposition 9: We will prove the proposition in a sequence of various lemmas.

Lemma A: If firm $i$ is a monopolist at date $t \geq t_{i}^{1}=G_{1}^{-1}\left((r+\lambda) S_{i}-\lambda C\right)$, then it does not exit during the period of time in which it expects to be a monopolist and the market is expanding. If $t<t_{i}^{1}=G_{1}^{-1}\left((r+\lambda) S_{i}-\lambda C\right)$, then either it exits immediately or it does not exit.

Proof: Let us consider first the case of firm 1. Suppose that it chooses to exit before its rival entered (if such date exists and the market is still growing at such date). (The case in which it chooses to exit at or after its rival's entry is covered in the next lemma.) In order to decide its exit time $t^{\prime}$ given information at date $t$, firm 1 solves the following program:

$$
\begin{aligned}
\max _{t^{\prime} \geq t} X_{1}^{1}\left(t^{\prime} / t\right)= & \frac{1}{\operatorname{Pr}(t<\tau)}\left[\left(\int_{t^{\prime}}^{\infty} f(\tau) d \tau\right)\left(\int_{t}^{t^{\prime}} G_{1}(s) e^{-r s} d s+S_{1} e^{-r t^{\prime}}\right)+\right. \\
& \left.\int_{t}^{t^{\prime}} f(\tau)\left(\int_{t}^{\tau} G_{1}(s) e^{-r s} d s+\int_{\tau}^{t_{1}^{x}(1, \tau)} D_{1}(s-\tau) e^{-r s} d s+S_{1} e^{-r r_{1}^{*}(1, \tau)}\right) d \tau\right]
\end{aligned}
$$

Since $X_{1}^{1}\left(t^{\prime} / t\right)$ is a strictly quasi-convex function with a global minimum at $t_{1}^{1}=G_{1}^{-1}\left((r+\lambda) S_{1}-\lambda C\right)$, the function is strictly increasing on $t \geq t_{1}^{1}$, and, thus, it follows 
that firm 1 is not willing to exit a growing market whenever it is a monopolist at $t \geq t_{i}^{1}$.

For $t<t_{i}^{1}$, the strict quasi-convexity of $X_{1}^{1}\left(t^{\prime} / t\right)$ implies that firm 1's optimal action is either exit immediately or not to exit before $\tau$ is revealed.

The proof for firm 2 is similar.

Lemma B: If firm $i$ is a duopolist at date $t \geq t_{i}^{2}=G_{2}^{-1}\left((r+\lambda) S_{i}-\lambda A\right)$, then it does not exit during the period of time in which it expects to be a duopolist and the market is expanding. If $t<t_{i}^{2}=G_{2}^{-1}\left((r+\lambda) S_{i}-\lambda A\right)$, then either it exits immediately or it does not exits.

Proof: Similar to that of Lemma A.

Denote the set of dates at which firm $i(i=1,2)$ is not willing to exit (immediately) when $m$ firms are active $(m=1,2)$ by $T_{i}^{m}$. By Lemmas A and $\mathrm{B}, T_{i}^{m}$ is not empty.

Lemma C: If $t \in T_{i}^{m}$, then $\hat{t} \in T_{i}^{m}$ for all $\hat{t}>t$.

Proof: Suppose to the contrary that $t \in T_{i}^{m}$, but $\hat{t} \notin T_{i}^{m}$ for some $\hat{t}>t$. In particular, consider $\hat{t}=\inf \left\{s>t: s \notin T_{i}^{m}\right\}$, with $\hat{t} \notin T_{i}{ }^{m}{ }^{33}$ It is clear that firm $i$ would exit immediately at $\hat{t}$ by Lemmas A and B (it could be indifferent between immediate exit and no exit, so in case of indifference, we are assuming that it chooses to exit immediately rather than remain in the market). Now consider date $\hat{t}-\varepsilon$, for $\varepsilon>0$ sufficiently small. At such date, firm $i$ prefers to remain in the market as long as the market is growing, by definition of $\hat{t}$. But, given that it plans to exit (almost) immediately at $\hat{t}$, it can be proven that the firm would be better off exiting, which would

\footnotetext{
${ }^{33}$ If $\hat{t} \in T_{i}^{m}$, just reverse the roles of $\hat{t}$ and $\hat{t}-\varepsilon$ in the proof below, and let $\varepsilon<0$ be sufficiently large.
} 
entail the desired contradiction since $\hat{t}-\varepsilon$ is assumed to belong to the no exit region. The proof for $i=1$ and $m=2$ (the proofs for the other cases are similar, if not simpler) is as follows. If firm 1 waits to exit until $\hat{t}$, then it expects to gain:

$$
\begin{aligned}
& X_{1}^{1}(\hat{t} / \hat{t}-\varepsilon)=\frac{1}{\operatorname{Pr}(\hat{t}-\varepsilon<\tau)}\left[\left(\int_{\hat{t}}^{\infty} f(\tau) d \tau\right)\left(\int_{\hat{t}-\varepsilon}^{\hat{t}} G_{2}(s) e^{-r s} d s+S_{1} e^{-r \hat{t}}\right)+\right. \\
& \left.\int_{\hat{t}-\varepsilon}^{\hat{t}} f(\tau)\left(\int_{\hat{t}-\varepsilon}^{\tau} G_{2}(s) e^{-r s} d s+\int_{\tau}^{t_{1}^{x}(1, \tau)} D_{2}(s-\tau) e^{-r s} d s+\int_{t_{2}^{x}(2, \tau)}^{t_{1}^{x}(1, \tau)} D_{1}(s-\tau) e^{-r s} d s+S_{1} e^{-r t_{1}^{x}(1, \tau)}\right) d \tau\right]= \\
& \frac{1}{(1+\lambda \varepsilon) e^{-\lambda \hat{t}}}\left\{\left(\varepsilon G_{2}(\hat{t}) e^{-r \hat{t}}+S_{1} e^{-r \hat{t}}\right) \int_{\hat{t}}^{\infty} f(\tau) d \tau+\varepsilon^{2} f(\hat{t}) G_{2}(\hat{t}) e^{-r \hat{t}}+\varepsilon A f(\hat{t}) e^{-r \hat{t}}\right\}= \\
& \left.\varepsilon G_{2}(\hat{t})\right) e^{-r \hat{t}}+\frac{e^{\lambda \hat{t}}\left(S_{1} e^{-(r+\lambda) \hat{t}}+\varepsilon \lambda A e^{-(r+\lambda) \hat{t}}\right)}{1+\lambda \varepsilon},
\end{aligned}
$$

where we have used the facts that $e^{\rho \varepsilon}=1+\rho \varepsilon$ for a small $\varepsilon, f(\tau)=\lambda e^{-\lambda \tau}$ and the definition of $A$.

By immediately exiting at $\hat{t}-\varepsilon$, firm 1 would seize $S_{1} e^{-r(\hat{t}-\varepsilon)}=S_{1} e^{-r \hat{t}}+\varepsilon r S_{1} e^{-r \hat{t}}$. We claim that this payoff is greater than $X_{1}^{1}(\hat{t} / \hat{t}-\varepsilon)$ for sufficiently small $\varepsilon>0$. Suppose to the contrary that $\left.S_{1} e^{-r \hat{t}}+\varepsilon r S_{1} e^{-r \hat{t}} \leq \varepsilon G_{2}(\hat{t})\right) e^{-r \hat{t}}+\frac{e^{\lambda \hat{t}}\left(S_{1} e^{-(r+\lambda) \hat{t}}+\varepsilon \lambda A e^{-(r+\lambda) \hat{t}}\right)}{1+\lambda \varepsilon}$. Multiplying through by $\frac{e^{r \hat{t}}(1+\lambda \varepsilon)}{\varepsilon}>0$, canceling terms, and letting $\varepsilon \rightarrow 0$ yields $(r+\lambda) S_{1} \leq G_{2}(\hat{t})+\lambda A$, so $\hat{t} \geq t_{1}^{2}$, which contradicts Lemma B

Now let $[0, \infty) \backslash T_{i}^{m}$ be the immediate exit region for firm $i$ when $m$ firms are active in the market. If the set $[0, \infty) \backslash T_{i}^{m}$ is empty, then the proof of the proposition is finished. The following lemma delivers the desired result when it is non-empty. 
Lemma D: Firm $i$ has no incentives to enter the market at $t \in[0, \infty) \backslash T_{i}^{m}$ so that $m$ firms are active at that date.

Proof: Follows trivially from the facts that $K e^{-r t}>S_{i} e^{-r t}$ and $S_{i} e^{-r t}$ is not smaller than the payoff to remaining in a market with $m$ firms while it is growing if $t \in[0, \infty) \backslash T_{i}^{m}$.

Thus, it follows from Lemmas C and D that it is optimal for active firms not to exit before the market begins its decline. 


\section{INDEX OF FIGURES}

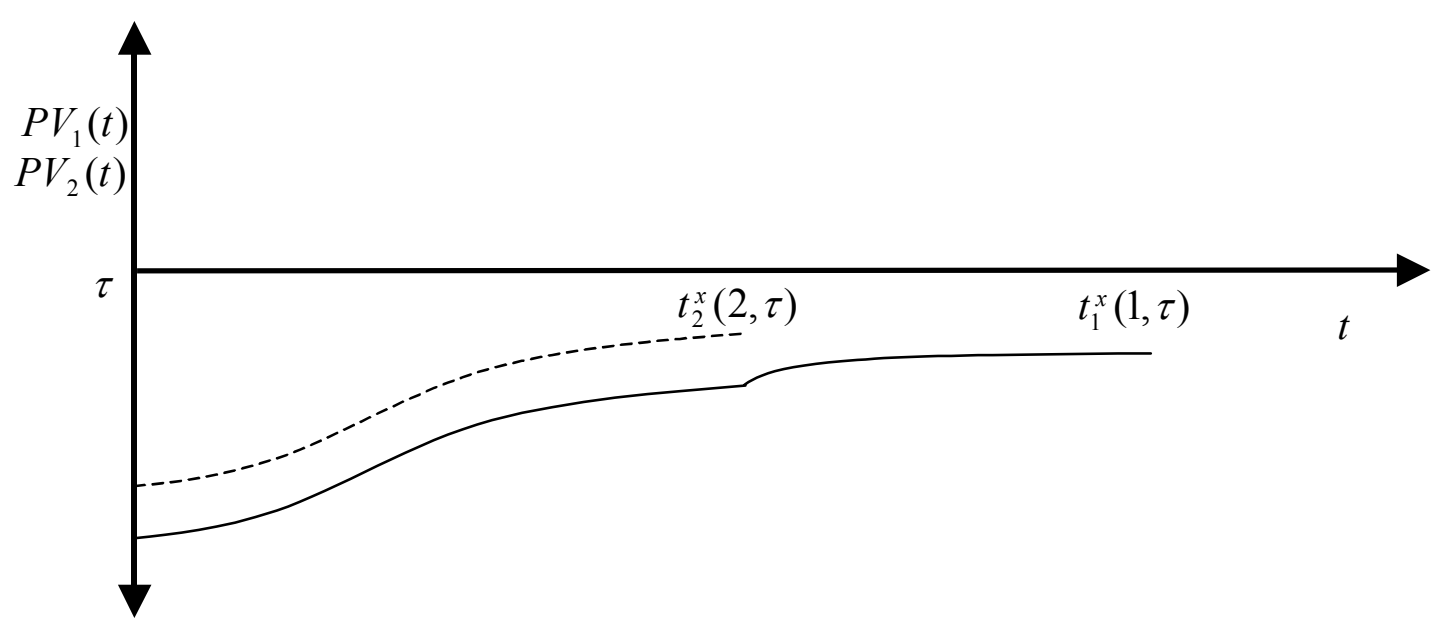

Figure 1: Payoff to entry into a declining market monopolized by the rival firm

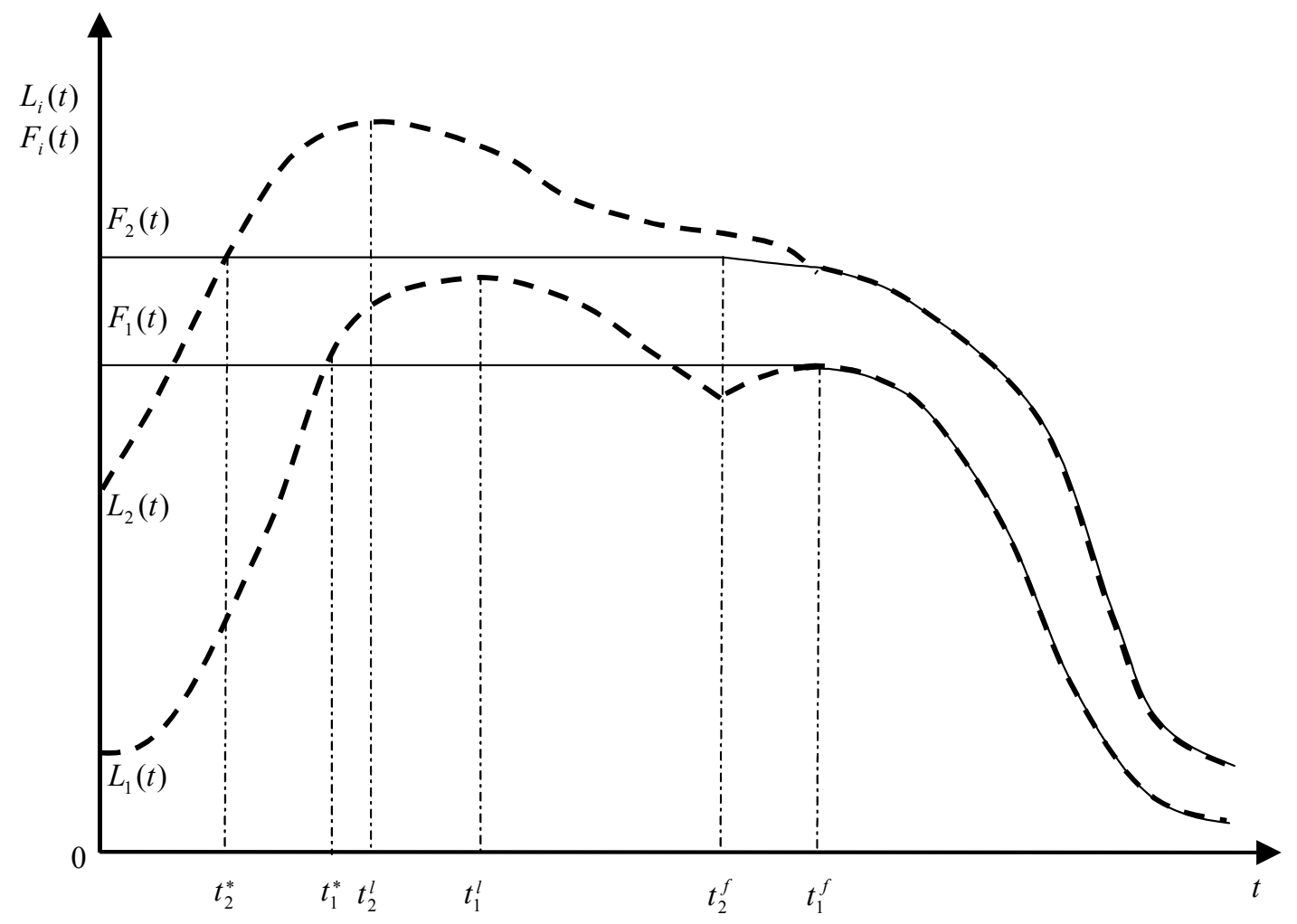

Figure 2: Entry game when $t_{2}^{l}<t_{1}^{l}<t_{2}^{f}<t_{1}^{f}$ 


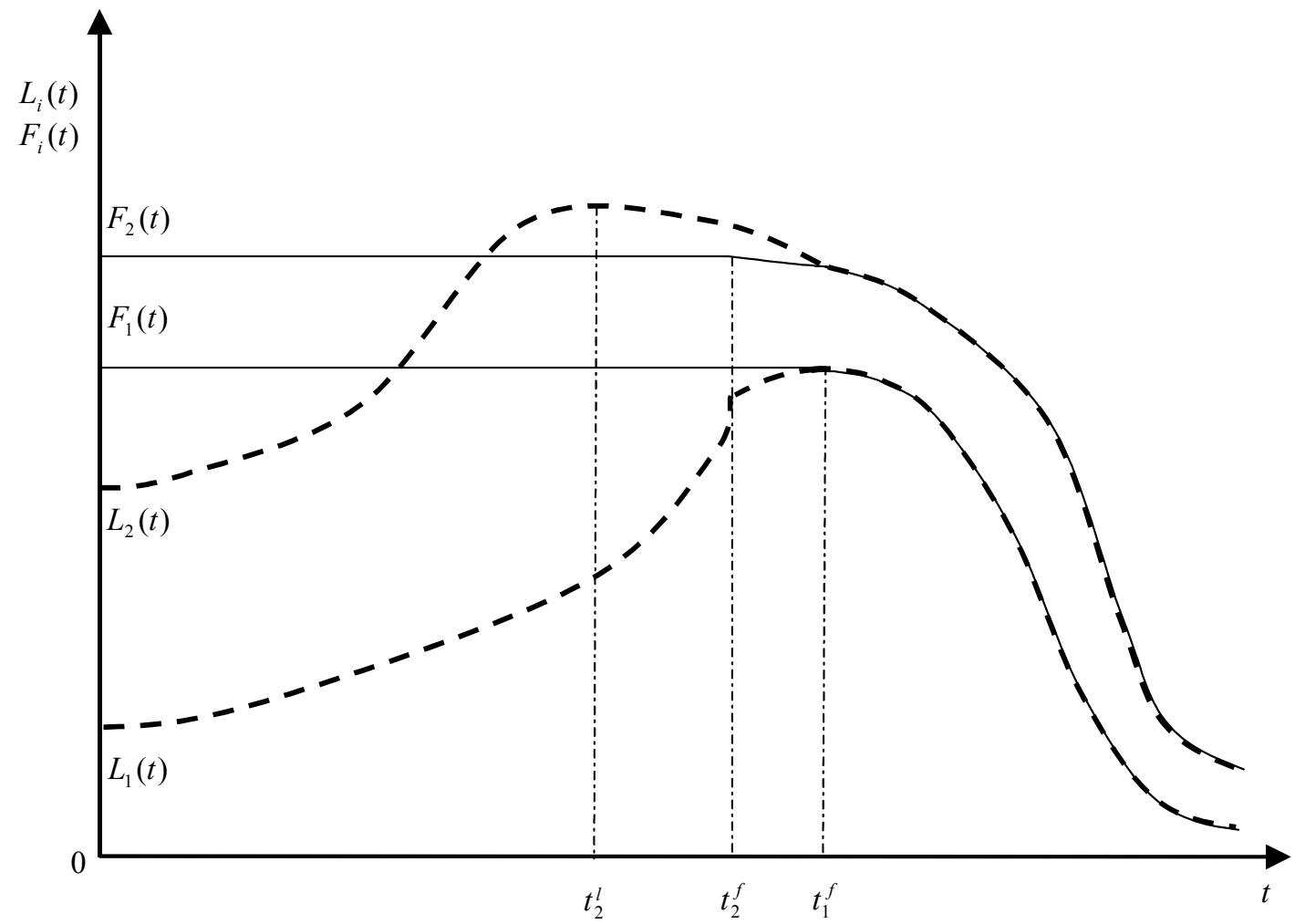

Figure 3: Entry game when $t_{2}^{l}<t_{1}^{f}<t_{2}^{f}$

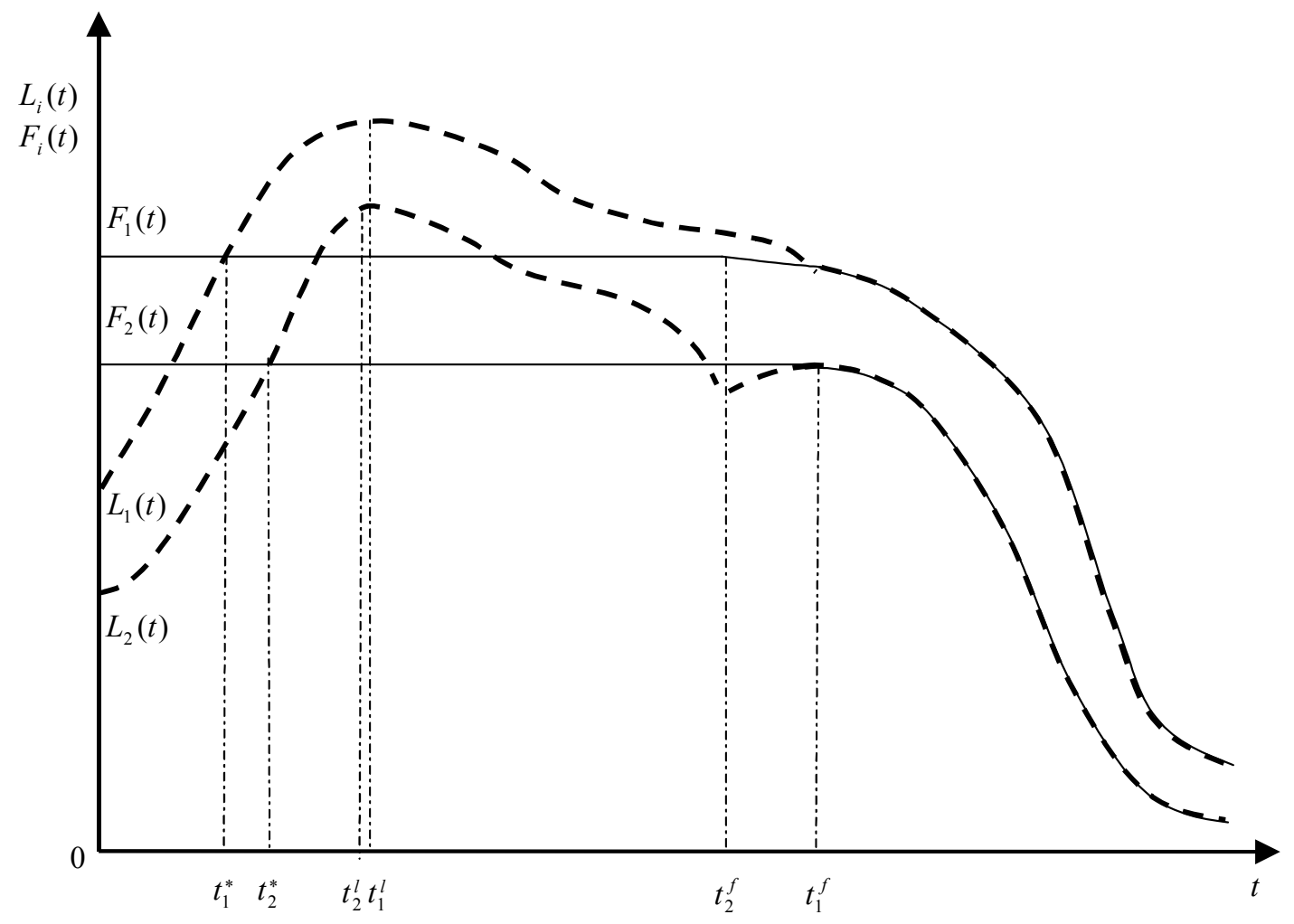

Figure 4: Entry game when $t_{2}^{l}<t_{1}^{l}<t_{1}^{f}<t_{2}^{f}$ 


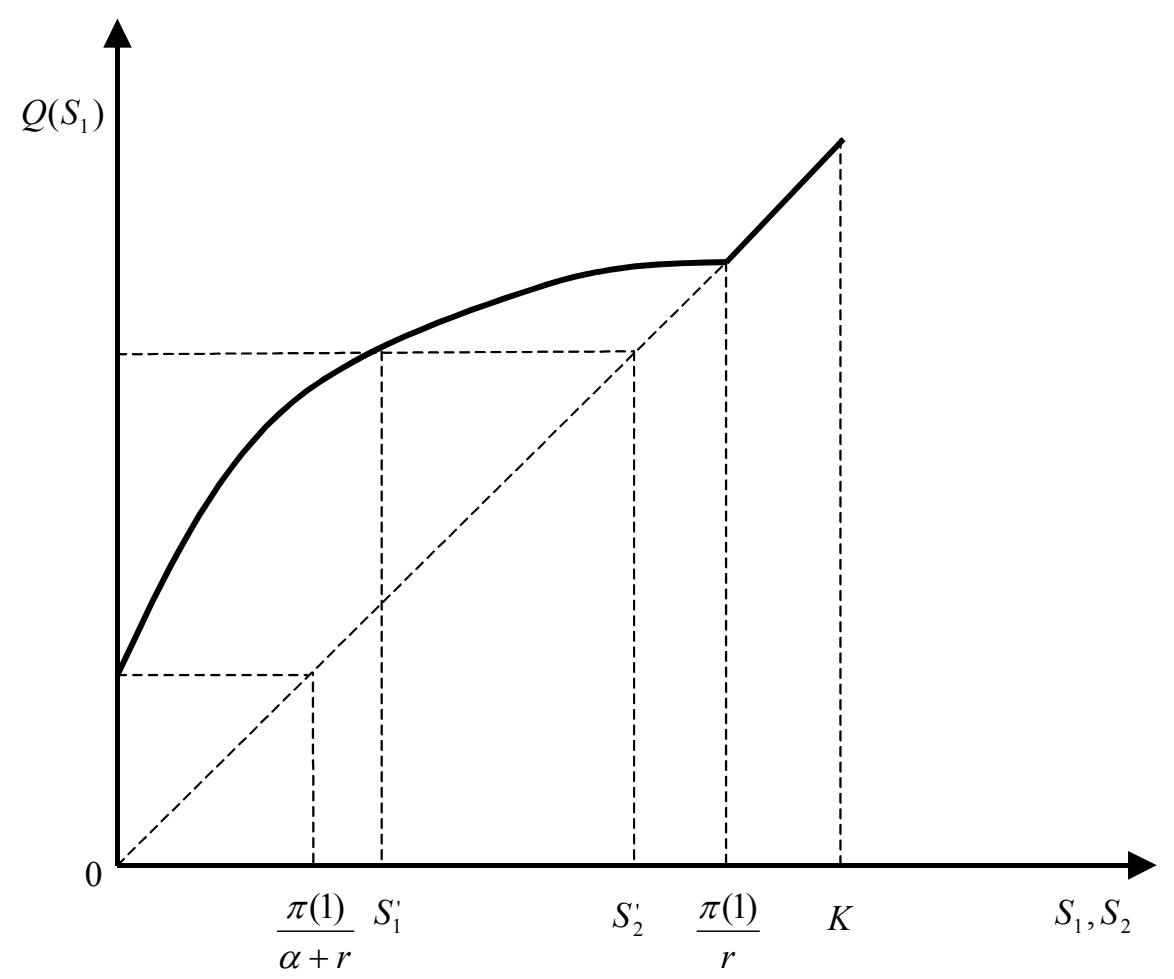

Figure 5

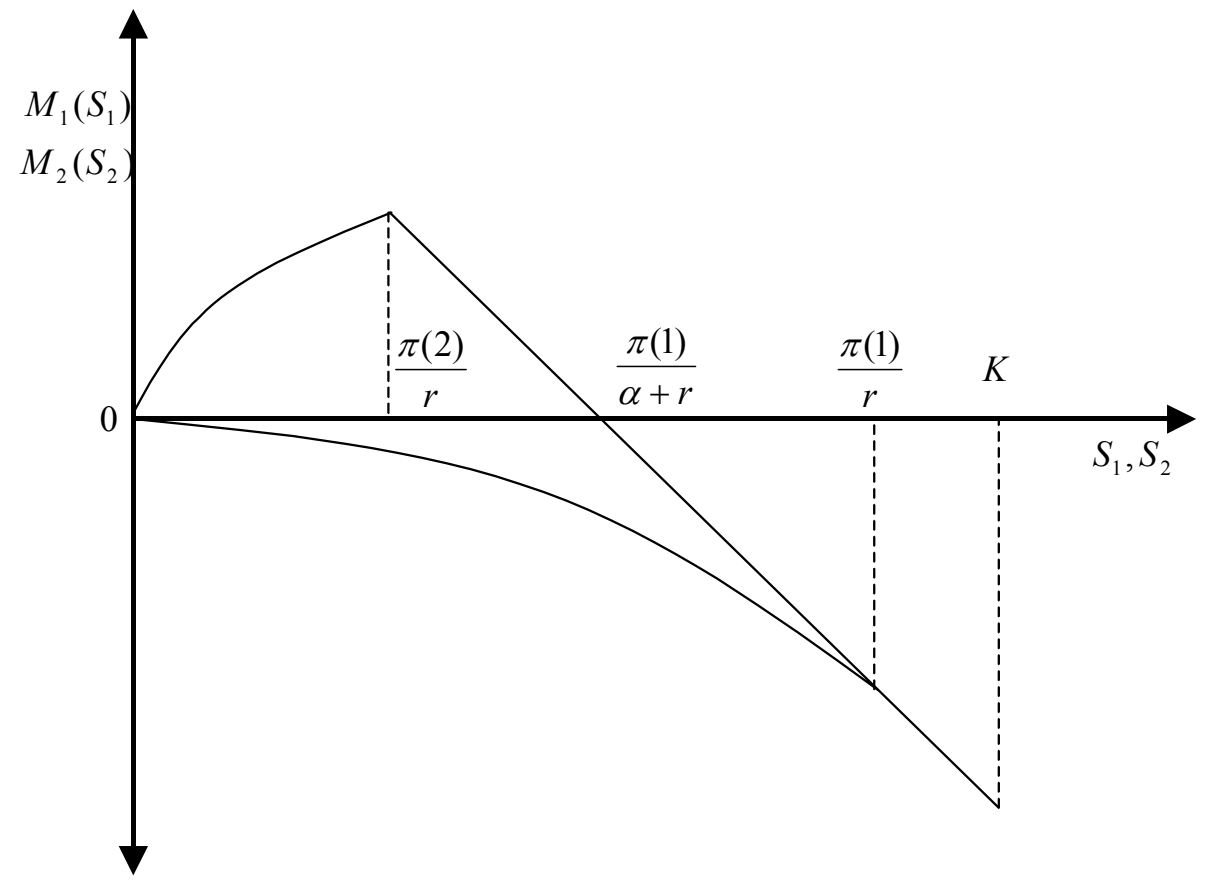

Figure 6 